\title{
The influence of Canadian research on semiochemical-based management of forest insect pests in Canada
}

\author{
Maya L. Evenden, ${ }^{1}$ Peter J. Silk
}

\begin{abstract}
Insects use semiochemicals to mediate important behaviours such as mating, oviposition, and foraging for resources. Chemical ecology research aims to identify these message-bearing chemicals and develop synthetic copies of semiochemicals for use in integrated pest management (IPM). There has been, and continues to be, an extensive research effort to understand the chemical ecology of various insects considered to be pests of forests in Canada. Canadian chemical ecology research has had an impact on IPM of forest insect pests in Canada and around the world. Canadian researchers have been involved in the identification of semiochemicals used by forest insects and the development and implementation of semiochemical-based management tactics for forest pest management. Semiochemicals have been incorporated into forest pest management for a variety of insect taxa primarily as tools to monitor and control forest insect pests in Canada. The goals of the current review are to: (1) highlight research conducted on semiochemical-based management of forest pests in Canada; (2) discuss the current and potential uses of semiochemicals in IPM of forest pests in Canada; and (3) evaluate potential areas for increased research and implementation of semiochemicals into the management of forest pests in Canada.
\end{abstract}

\section{Introduction}

There is a rich history of research on the chemical ecology of forest insects conducted by forest entomologists and chemical ecologists in Canada. Canadian researchers have been involved in the identification (Table 1), development, and implementation of semiochemical-based pest management as part of sustainable forest management in Canada (Fig. 1). Forest insect pests are good targets for management with semiochemicals because forest pest management is often focussed on a key pest at a given time in a given location. This makes the use of speciesspecific signals a feasible option that might not be realised in agricultural or urban settings where mangers frequently deal with pest complexes (Borden 1993). Semiochemicals are an integral part of integrated pest management (IPM) of insects considered to be forestry pests in Canada. This review will highlight the efforts of
Canadian researchers in the implementation of semiochemical-based tools into various aspects of IPM of forest insect pests (Fig. 1). Although the research conducted in Canada has been adopted in other countries around the world, the focus of this review is semiochemical-based management of forest insects in Canada that has been implemented as a result of Canadian research.

\section{What are semiochemicals?}

Most insects use message-bearing chemicals, or semiochemicals (Nordlund and Lewis 1976), to facilitate important behaviours such as mating, oviposition, and foraging for resources. Semiochemicals have been classified into several functional categories based on the type of signal they communicate and the relationship between the receiver and the signaller in the communication channel. Pheromones are semiochemicals that are species-specific signals used for intraspecific communication. Pheromones can mediate mate

Received 28 November 2014. Accepted 13 January 2015. First published online 11 June 2015.

M.L. Evenden, ${ }^{1}$ CW 405 Biological Sciences Building, University of Alberta, Edmonton, Alberta, Canada T6G 2E9 P.J. Silk, Atlantic Forestry Centre, Canadian Forest Service, 1350 Regent Street, P.O. Box 4000 Fredericton, New Brunswick, Canada E3B 5P7

${ }^{1}$ Corresponding author (e-mail: mevenden@ualberta.ca).

Langor, D.W. and Alfaro, R.I. (eds.) Forest Entomology in Canada: Celebrating a Century of Science Excellence doi:10.4039/tce.2015.17 
Table 1. Identification and/or field testing of pheromones of Canadian forest pests conducted in Canada.

Insects

Common name

Latin name (Family name)

Type of

pheromone

References

Coleoptera

Emerald ash borer

Agrilus planipennis (Buprestidae)

White pine cone beetle

Contact sex

Silk et al. (2009)

Conophthorus coniperda (Curculionidae)

Lodgepole cone beetle

Birgersson et al. (1995)

Conophthorus ponderosae (Curculionidae)

Red pine cone beetle

Miller et al. (2000)

Conophthorus resinosae (Curculionidae)

Douglas-fir beetle

Dendroctonus pseudotsugae (Curculionidae)

Spruce beetle

Dendroctonus rufipennis (Curculionidae)

Dryocoetes affaber (Curculionidae)

Western balsam bark beetle

Dryocoetes confusus (Curculionidae)

Gnathotrichus retusus (Curculionidae)

Gnathotrichus sulcatus (Curculionidae)

Ips latidens (Curculionidae)

Pine engraver

Ips pini (Curculionidae)

Pityogenes knechteli (Curculionidae)

Pityokteines elegans (Curculionidae)

Four-eyed spruce beetle

Polygraphus rufipennis (Curculionidae)

Tetropium cinnamopterum (Cerambycidae)

Brown spruce longhorned beetle

Tetropium fuscum (Cerambycidae)

Trypodendron betulae (Curculionidae)

Striped ambrosia beetle

Trypodendron lineatum (Curculionidae)

Trypodendron retusum (Curculionidae)

Diptera

Douglas-fir cone midge

Pierce et al. (1995)

Aggregation

Lindgren et al. (1992)

Aggregation

Gries et al. (1988, 1992), Borden et al. (1996)

Aggregation

Camacho et al. (1994)

Aggregation

Antiaggregation

Aggregation

Borden et al. (1987b), Camacho et al. (1993)

Aggregation

Aggregation

Antiaggregation

Stock et al. (1990)

Borden et al. (1980b)

Byrne et al. (1974)

Miller et al. (1991)

Miller et al. (1990)

Aggregation

Savoie et al. (1998)

Aggregation

Macias-Samano et al. (1997)

Aggregation

Bowers et al. (1991)

Aggregation

Silk et al. (2007)

Aggregation

Silk et al. (2007)

Aggregation

Kühnholz (2004)

Aggregation

MacConnell et al. (1977)

Aggregation

Kühnholz (2004)

Sex

Gries et al. (2002)

Contarina oregonensis (Cecidomyiidae)

Red cedar cone midge

Sex

Gries et al. (2005a)

Mayetiola thujae (Cecidomyiidae)

Hemiptera

Western conifer seed bug

Leptoglossus occidentalis (Coreidae)

Lepidoptera

Eastern blackheaded budworm

Acleris variana (Tortricidae)

Maple leafroller

Cenopis acerivorana (Tortricidae)

Spruce budworm

Alarm

Blatt et al. (1998)

$\operatorname{Sex}$

Gries et al. (1994a)

Sex Grant and Slessor (1983)

Sex Wiesner et al. (1979), Silk et al. (1980)

Choristoneura fumiferana (Tortricidae)

Western spruce budworm

Sex

Silk et al. (1982), Cory et al. (1982)

Choristoneura occidentalis (Tortricidae)

Choristoneura orae (Tortricidae)

Sex

Gray et al. (1984a) 
Table 1. Continued

\begin{tabular}{|c|c|c|}
\hline $\begin{array}{l}\text { Insects } \\
\text { Common name } \\
\text { Latin name (Family name) } \\
\end{array}$ & $\begin{array}{l}\text { Type of } \\
\text { pheromone }\end{array}$ & References \\
\hline $\begin{array}{l}\text { Jack pine budworm } \\
\text { Choristoneura pinus (Tortricidae) }\end{array}$ & Sex & Silk et al. (1985) \\
\hline $\begin{array}{l}\text { Oak leaf shredder } \\
\text { Croesia semipurpurana (Tortricidae) }\end{array}$ & Sex & Silk et al. (1997) \\
\hline $\begin{array}{l}\text { Spruce seed moth } \\
\text { Cydia strobiella (Tortricidae) }\end{array}$ & Sex & Bedard et al. (2002) \\
\hline $\begin{array}{l}\text { Fir coneworm } \\
\text { Dioryctria abietivorella (Pyralidae) }\end{array}$ & Sex & Grant et al. (2009), Millar et al. (2005) \\
\hline Dioryctria reniculelloides (Pyralidae) & Sex & Grant et al. (1987a) \\
\hline Dioryctria resinosella (Pyralidae) & Sex & Grant et al. (1993) \\
\hline $\begin{array}{l}\text { Elm spanworm } \\
\text { Ennomos subsignaria (Geometridae) }\end{array}$ & Sex & Ryall et al. (2010) \\
\hline $\begin{array}{l}\text { Saddled prominent } \\
\text { Heterocampa guttivitta (Notodontidae) }\end{array}$ & Sex & Silk et al. (2000) \\
\hline $\begin{array}{l}\text { Spring hemlock looper } \\
\text { Lambdina athasaria (Geometridae) }\end{array}$ & Sex & Gries et al. (1994b) \\
\hline $\begin{array}{l}\text { Hemlock looper } \\
\text { Lambdina fiscellaria fiscellaria } \\
\text { (Geometridae) }\end{array}$ & Sex & Li et al. (1993b) \\
\hline $\begin{array}{l}\text { Western hemlock looper } \\
\text { Lambdina fiscellaria lugubrosa } \\
\text { (Geometridae) }\end{array}$ & Sex & Gries et al. (1993a), Li et al. (1993a) \\
\hline $\begin{array}{l}\text { Gypsy moth } \\
\text { Lymantria dispar (Erebidae) }\end{array}$ & Sex & Gries et al. $(1996,2005 b)$ \\
\hline $\begin{array}{l}\text { Forest tent caterpillar } \\
\text { Malacosoma disstria (Lasiocampidae) }\end{array}$ & Sex & Chisholm et al. (1980) \\
\hline $\begin{array}{l}\text { Western false hemlock looper } \\
\text { Nepytia freemani (Geometridae) }\end{array}$ & Sex & Gries et al. (1993c), King et al. (1995) \\
\hline $\begin{array}{l}\text { Live oak tussock moth } \\
\text { Orgyia detrita (Erebidae) }\end{array}$ & Sex & Gries et al. (2003) \\
\hline $\begin{array}{l}\text { Whitemarked tussock moth } \\
\text { Orgyia leucostigma (Erebidae) }\end{array}$ & Copulation release & Grant et al. (1987b) \\
\hline $\begin{array}{l}\text { Douglas-fir tussock moth } \\
\text { Orgyia pseudotsugata (Erebidae) }\end{array}$ & Sex & Gries et al. (1997) \\
\hline $\begin{array}{l}\text { European pine shoot moth } \\
\text { Rhyacionia buoliana (Tortricidae) }\end{array}$ & Sex & Gray et al. (1984b) \\
\hline $\begin{array}{l}\text { Larch looper } \\
\text { Semiothisa sexmaculata (Geometridae) }\end{array}$ & Sex & Gries et al. (1993b) \\
\hline $\begin{array}{l}\text { Spruce budmoth } \\
\text { Zeiraphera canadensis (Tortricidae) }\end{array}$ & Sex & Silk et al. (1989) \\
\hline $\begin{array}{l}\text { Purplestriped shootworm } \\
\text { Zeiraphera unfortunana (Tortricidae) }\end{array}$ & Sex & Silk et al. (1988) \\
\hline
\end{tabular}

location, courtship, aggregation, alarm, and spacing of insects throughout a resource. Sex pheromones that are released by one sex and evoke a response in the other sex for the purposes of mate location and aggregation pheromones that are released by one sex and evoke a response in both sexes are the most common pheromones exploited in IPM.

Allelochemics are semiochemicals that are emitted by individuals of one species and perceived 
Fig. 1. Research and development required to implement semiochemicals into IPM programmes. Solid arrows indicate flow of information. Dashed arrows indicate information that could be used to refine the semiochemicalbased tactic.

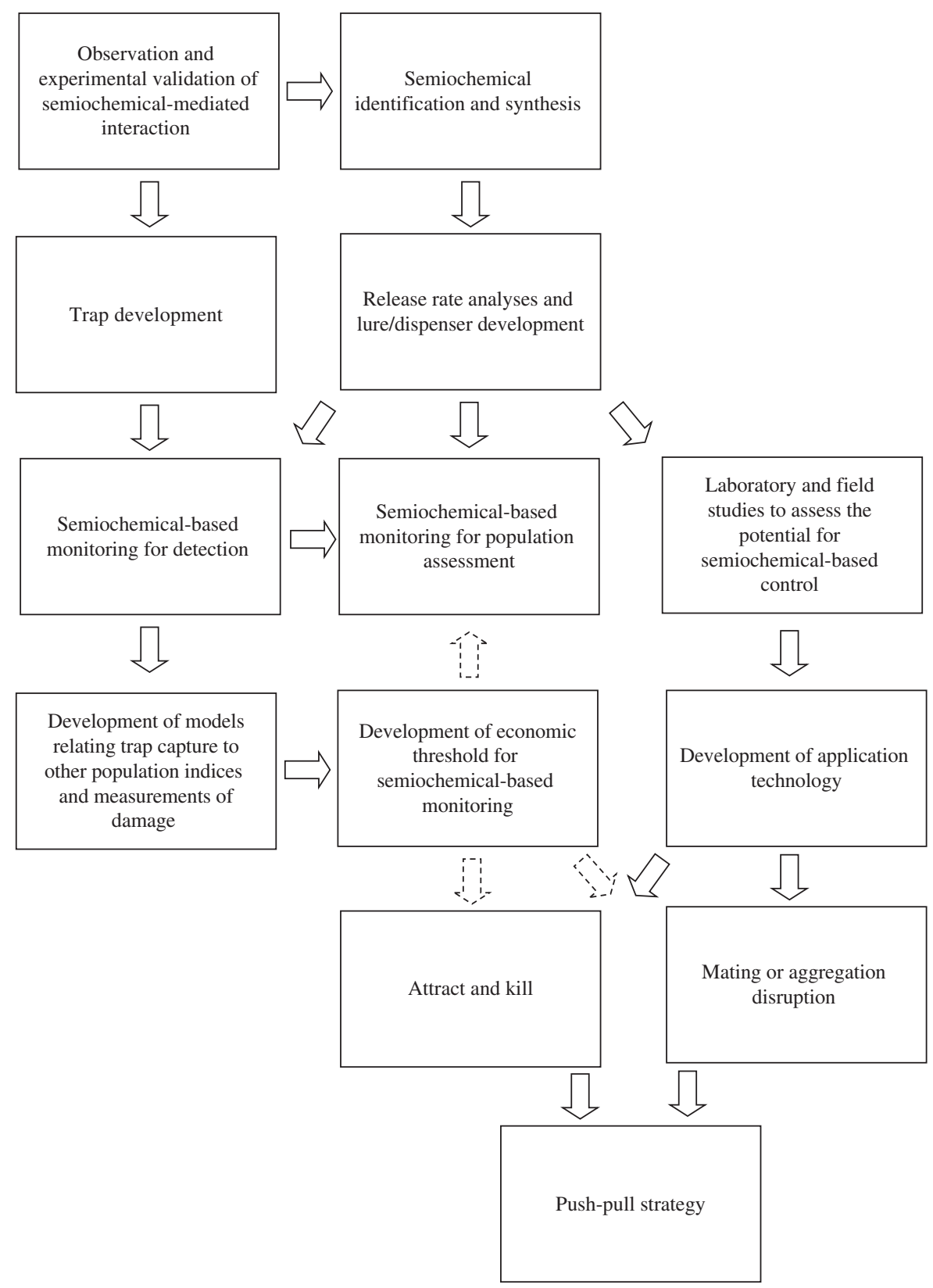

by individuals of a different species (Whittaker and Feeny 1971). In many instances, allelochemics have evolved as signals for intraspecific communication, which are subsequently exploited as reliable signals by other organisms (Haynes and
Yeargan 1999). Allelochemics are further categorised by the type of interspecific interaction that they mediate. Kairomones mediate an interaction that benefits the receiver of the signal, such as orientation of predaceous checkered beetles 
(Coleoptera: Cleridae) to the aggregation pheromones of their bark beetle prey (Coleoptera: Curculionidae: Scolytinae) (Poland and Borden 1997). Allomones are semiochemicals that mediate an interaction that is beneficial to the emitter of the signal. Aggressive chemical mimicry employing allomones occurs in arthropods, whereby the signalling species mimics a chemical signal that is similar to that used for intraspecific communication in the receiving species (Haynes and Yeargan 1999). The receiver is "duped" into responding to the allomone and often becomes the prey item of the signaller. Synomones are semiochemicals that mediate an interspecific interaction that is beneficial to both the emitter and receiver of the signal. Herbivore-induced plant volatiles act as synomones that recruit natural enemies of the herbivore to the affected plant (Turlings et al. 1990). In mate-finding communication, synomones act to reduce competition in the chemical communication channel among closely related species with overlapping pheromone components (Evenden et al. 1999) to prevent wasted time and energy in orientation to heterospecifics.

The reliance of insects on semiochemicals for reproduction and survival makes them good targets for use in IPM. Various stages of research and development (Fig. 1) need to occur before semiochemicals can be incorporated into IPM programmes.

\section{Monitoring pests with semiochemicals}

Insect semiochemicals can be used in IPM for both monitoring and direct control of pest populations (Gut et al. 2004; Baker and Heath 2005; Witzgall et al. 2010). The most common commercial application of semiochemicals in pest management is for monitoring pest populations (Witzgall et al. 2010), and the majority of these products use synthetic copies of species-specific pheromone signals as lures in traps. There are several advantages to using pheromones to monitor pest populations: (1) signals are species specific and usually few non-target species are captured; (2) signals can attract insects from a distance and monitor low pest population densities; and (3) only small quantities of the active ingredient are necessary to elicit a response (Witzgall et al. 2010). Several pest management strategies employ pheromone-baited traps to monitor populations for different purposes.
In the simplest way, pheromone-based monitoring can determine the presence of a given insect species in a forest ecosystem. Because pheromone-baited traps are more sensitive than many other sampling tools, this approach is particularly useful to detect the introduction and spread of invasive species on a landscape (Sweeney et al. 2006). This approach has been widely used in Canada to monitor the introduction and spread of gypsy moth, Lymantria dispar (Linnaeus) (Lepidoptera: Erebidae) (Nealis 2009). Beyond detection of the presence of an insect, capture of the target insect over time can provide information on the diel periodicity of pheromone response (Shepherd 1979) and the seasonal flight period (Grant et al. 2002; Rocchini et al. 2003) and, in combination with phenological models, can be used to help time control measures (Régnière and Nealis 2002). Trap catch in pheromone-baited traps was used to develop a degree-day model, which is used to predict adult emergence in the pine shoot moth, Rhyaciona buoliana (Denis and Schiffermüller) (Lepidoptera: Tortricidae) in order to time the application of control sprays in lodgepole pine seed orchards in British Columbia, Canada (Heeley et al. 2003).

Additional information about the population can be garnered from closer examination of the trapped insects, such as sex ratio (Borden et al. 2008), mating status (Bergh et al. 1988), size and disease status (Sweeney and McLean 1987; Jones and Evenden 2008). These factors can be useful in determining the population phase of forest insects that undergo cyclical changes in population density. Pheromone-baited traps can also be used to measure genetic diversity of captured insects, which can be used to trace the path of invasion in introduced species (Carter et al. 2009). Pheromone response, as a phenotypic trait, can be used to delineate species within closely related species complexes or to uncover otherwise cryptic species (Sanders et al. 1977).

Pheromone-baited traps are less often developed to predict pest population densities and subsequent damage. This is because the relationship between trap catches and resulting damage is costly to develop and not very precise. In wellstudied cases, economic thresholds, based on the numbers of insects captured in pheromone-baited traps, can be developed to trigger management 
action (Fig. 1) (Grant 1991). Years of research led to the development of an operational pheromonebased monitoring system for the spruce budworm, Choristoneura fumiferana (Clemens) (Lepidoptera: Tortricidae) that can predict densities of larvae in the subsequent generation (Sanders 1988). In monitoring programmes for Douglas-fir tussock moth, Orgyia pseudotsugata (McDunnough) (Lepidoptera: Erebidae), pheromone trap capture combined with egg-mass surveys predict population concentrations and potential defoliation in Douglas-fir stands (Shepherd et al. 1985). Pheromone-based monitoring is particularly useful for monitoring forest insect pests that go through cyclical changes in population density in which insect abundance can increase quickly and result in widespread damage.

\section{Control of pests with semiochemicals}

Semiochemicals can also be used to manipulate insect behaviour to interfere with reproduction and/or survival in order to control the pest population. Disruption of pheromone-mediated mating or aggregation behaviour is a pest management tactic that is achieved differently for different species. Mating disruption is normally achieved through the release of large amounts of synthetic sex pheromone to the managed area in an effort to disrupt mate-finding behaviour through a variety of mechanisms (Bartell 1982). This tactic has been best studied as a potential control for lepidopteran pests (Witzgall et al. 2010). The recent registration of a sprayable pheromone formulation to target the spruce budworm (Rhainds et al. 2012) in Canada suggests that commercial application of pheromone-based mating disruption can now be added to the IPM tactics used against this important forest defoliator. Disruption of semiochemical-mediated aggregation behaviour has been attempted for tree-killing bark beetles (Coleoptera: Curculionidae: Scolytinae). Recent studies focussed on the use of antiaggregation pheromones (Borden et al. 2007) and non-host plant volatiles (Huber and Borden 2001a) to interrupt mate finding and host location behaviours in an effort to save high-value trees from colonisation (Borden et al. 2007). Disruption of bark beetle orientation away from host trees can be coupled with deployment of attractive semiochemicals in a "push-pull" tactic (Borden et al. 2006). This method is used to repel beetles away from high-value stands and concentrate them in areas from which they can be easily removed.

Population control can also be achieved by attracting the target insect pest to a semiochemical lure and subsequent removal of the attracted pest from the population. This strategy can be achieved using "attract and kill" or mass-trapping tactics. Attract-and-kill formulations combine an attractant and a killing agent to kill the attracted pest. This approach is well suited to bark-beetle management because both male and female beetles respond to aggregation pheromones and tree host volatiles in the tree colonisation process (Conn et al. 1983). Synthetic copies of these attractants can be used to bait trap logs that are coated with insecticide (Fuchs and Borden 1985) or trap trees that are injected with insecticide (Maclauchlan et al. 1988) or felled and stripped or burned after beetle attack (Borden 1990). Perhaps because only males are attracted to lepidopteran sex pheromones, attract-and-kill tactics have been less widely developed for lepidopteran forest defoliators. Several formulations show promise for control of pests of managed seed orchards (Sukovota et al. 2004). In these cases, the formulations contain synthetic sex pheromone as the attractant and pyrethroid insecticides as the killing agent. Mass trapping is similar to attract and kill, except that the attracted insects are contained within a trap and are physically removed from the population. Due to the cost of deploying large numbers of traps into a forested ecosystem, mass trapping is restricted to use in high-value stands (Borden 1993) or small, discrete managed areas such as dry-land sorts (Lindgren and Fraser 1994).

\section{Goals of review}

Earlier reviews have focussed on the potential to use semiochemicals to: (1) manage coniferous forest pests of North America (Borden 1993); (2) control forest Lepidoptera in eastern Canada (Silk and Kuenen 1984); (3) monitor forest defoliators in North America (Grant 1991); or (4) mitigate aggregation behaviour of bark beetles (Borden 1997). Other reviews have specifically targeted semiochemical management of key forest pests, such as the mountain pine beetle, Dendroctonus ponderosae Hopkins (Coleoptera: Curculionidae) (Borden and Lindgren 1989) or 
the spruce budworm (Rhainds et al. 2012). The goals of the current review are to: (1) highlight research conducted on semiochemical-based management of forest pests in Canada; (2) discuss the current and potential uses of semiochemicals in IPM of forest pests in Canada; and (3) evaluate potential areas for increased research and implementation of semiochemicals into the management of forest pests in Canada.

\section{Use of semiochemicals in management of forest defoliators}

\section{Monitoring forest defoliators}

Monitoring is the pest management strategy that most commonly incorporates the use of semiochemicals in IPM (Witzgall et al. 2010). Semiochemical-based monitoring of forest defoliators uses mostly sex pheromone-baited traps to detect the presence of a species in a given area or to monitor population change over time. Monitoring programmes along this continuum have existed at the research to operational scales for at least 19 species of forest defoliators in Canada (Grant 1991). Systematic pheromone-based monitoring of forest defoliators across Canada has become a multi-jurisdictional responsibility under the purview of the Canadian Council of Forest Ministers (Canadian Council of Forest Ministers 2012).

Monitoring for detection: The gypsy moth, an insect pest of over 300 hardwood tree species, was accidentally introduced into the United States of America in the late 1860s. Since then, its range has expanded in North America (Liebhold et al. 1998) and it is now established in eastern but not western Canada. This insect is a native of both Asia and Europe, with apparently two races that differ in size, flight characteristics, and host preferences. The Asian race is much larger than the European race, feeding on over 500 tree species and, in addition, both sexes of the Asian race are strong fliers compared with only males of the European race (Humble and Stewart 1994). Until recently, most research efforts were focussed on the European race, but in 1991, the Asian gypsy moth was discovered in Vancouver, British Columbia, Canada and in Washington, Oregon, and Ohio states, United States of America (Humble and Stewart 1994). The European race is now established in Ontario, Québec, New Brunswick, and Nova Scotia, Canada but, despite repeated introductions, has not yet established in British Columbia (Nealis 2009). The Asian race is not established anywhere in Canada and its occasional detection through pheromone-based trapping immediately triggers eradication efforts.

Early identification of the pheromone of the gypsy moth as cis-7,8-epoxy-2-methyloctadecane or disparlure, followed by the discovery that only the (+)-disparlure enantiomer mediates attraction of male moths (Cardé et al. 1977), paved the way for the use of pheromone-baited traps to detect and delimit populations of this insect. Delta traps baited with $500 \mu \mathrm{g}$ of (+)-disparlure (Grant 1991) are deployed annually across Canada. In British Columbia, where the European gypsy moth has been repeatedly introduced but has not established, pheromone-baited traps are deployed in a grid pattern at a density of one trap per $2.6 \mathrm{~km}^{2}$ (Nealis 2009) and play a key role in directing eradication efforts against this insect (Fig. 2). Positive moth capture triggers labour-intensive egg mass surveys, intensified trapping the following season and insecticidal control (Nealis 2009) (Fig. 2). Although different densities of traps on the landscape in different years make it difficult to compare population densities of gypsy moth over time, only detection is required to initiate actions to eradicate this insect in western Canada. Pheromone-baited traps are also used to assess the effectiveness of eradication efforts. Pheromone-baited traps are less useful in areas where gypsy moth is established, but are still used to delimit the edges of population growth in those regions (Nealis and Erb 1993).

Monitoring for population assessment: Management of native forest defoliators in Canada also relies on capture of male moths with pheromonebaited traps (Grant 1991). Detection of population change of native forest defoliators that undergo cyclical changes in population density can assist forest managers and provide time for management response before populations reach outbreak densities. Providing a reliable population estimate can be obtained, pheromone-baited traps can be a cheaper and less labour-intensive means of population monitoring compared with sampling immature stages or aerial surveys of defoliation (Sanders 1988). This type of monitoring is fundamentally different from that used in detection, 
Fig. 2. Use of pheromone-baited traps for detection of gypsy moth (Lymantria dispar Linnaeus (Lepidoptera: Erebidae)) to inform eradication efforts of this insect in British Columbia (B.C.) based on information in (Nealis 2009).

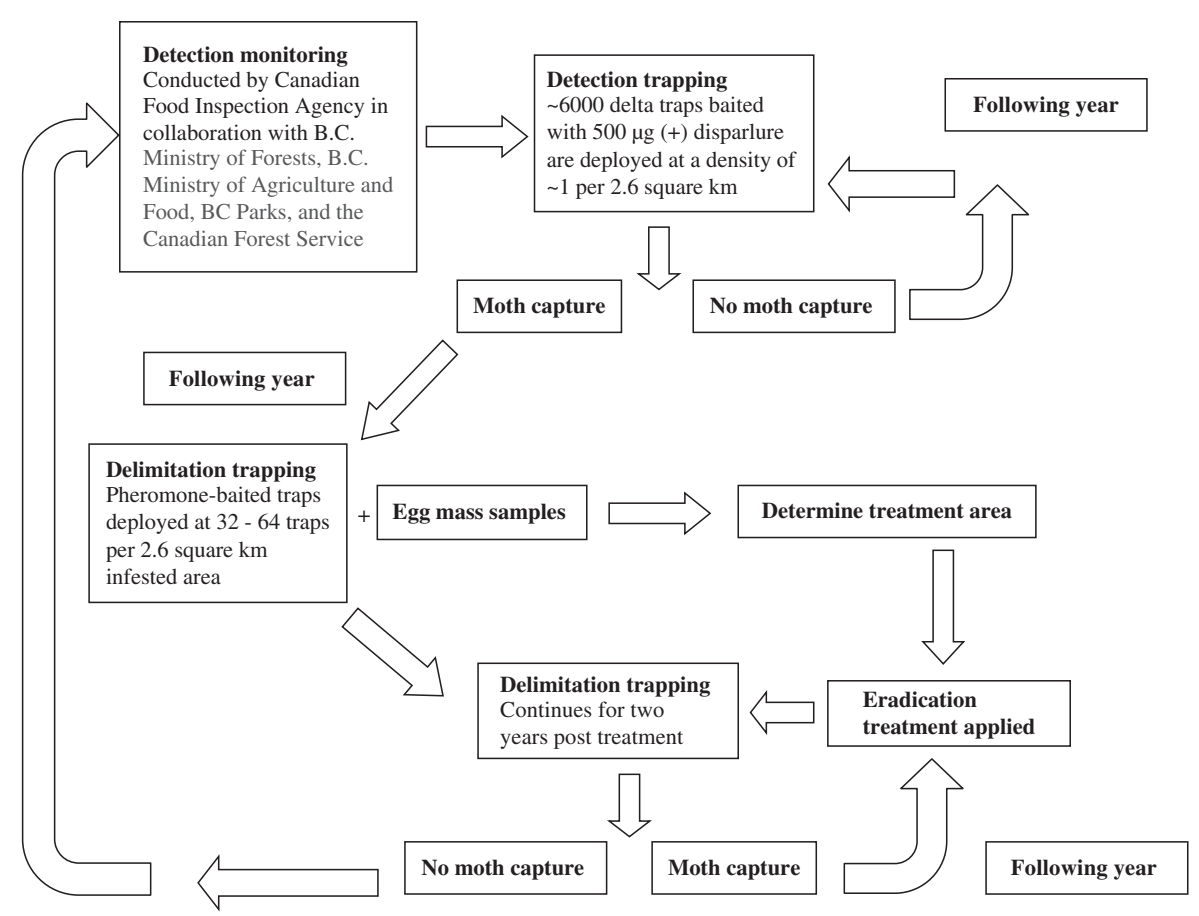

as moth capture in pheromone-baited traps needs to quantitatively reflect insect abundance. Consistency in sampling technique between years is required for monitoring of population assessment, and therefore development of an optimal trap and lure system is necessary before a monitoring system can be deployed (Grant 1991).

After identification of the sex pheromone itself (Table 1), some of the most important factors that influence the efficacy of a pheromone-based monitoring system are the lure type (Sanders and Meighen 1987), pheromone dose and the trap type (Evenden et al. 1995b) and the trap spacing and density at each site (Houseweart et al. 1981). Lure type and pheromone dose both can influence the active space (Byers 2008) of the pheromone plume and dictate the distance from which moths can be attracted and the period over which the lure remains attractive. A pheromone dose that is consistently effective at different population densities (Sanders 1986a), but does not necessarily elicit the highest trap capture, should be used (Shepherd et al. 1985). In fact, trap capture in low-dose pheromone-baited traps is easier to enumerate and can better reflect the actual population density than high-dose traps that capture more insects. Moths captured in traps baited with a low pheromone dose $(10 \mu \mathrm{g})$ targeting the western hemlock looper, Lambdina fiscellaria lugubrosa Guenée (Lepidoptera: Geometridae) predicted egg counts in the subsequent generation better than traps baited with higher doses (Evenden et al. 1995a). Similarly, moth capture in traps baited with a moderate pheromone dose of $0.01 \%$ pheromone by weight in polyvinyl chloride (PVC) rods best reflected population trends at various densities of the Douglas-fir tussock moth (Shepherd et al. 1985). The operational pheromonemonitoring programme for spruce budworm was developed using PVC pellets loaded with $0.03 \%$ synthetic pheromone (Sanders 1981, 1988). The attractiveness of PVC pellets declined over time during the six-week trapping period and showed variation between batches of lures (Sanders and Meighen 1987). Further research (Silk and Kuenen 1986; Sanders 1990) led to the development of 
rubber septa lures to provide a controlled release of spruce budworm pheromone suitable for seasonlong monitoring.

Early monitoring efforts relied on the use of sticky traps with a limited surface area for moth capture. Sticky traps are inexpensive but can quickly become saturated with insects as the population density increases, which can render the population estimate inaccurate. A direct comparison of trap capture of male western hemlock looper moths in sticky and non-saturating trap types showed that non-saturating traps captured significantly more males than similarly baited sticky traps at two different times in the flight period (Evenden et al. 1995b). Sticky traps fashioned from milk cartons with a $695 \mathrm{~cm}^{2}$ sticky trapping surface became saturated when 40 Douglas-fir tussock moths were captured. Because the cumulative capture of 25 Douglas-fir tussock moths indicates incipient outbreaks, sticky traps can still be used to monitor population assessment of this species (Shepherd et al. 1985). Non-saturating traps can retain large numbers of insects, which is particularly useful when traps remain in the field for the duration of the flight period. Even non-saturating Unitraps were less efficient in capturing western spruce budworm moths, Choristoneura occidentalis (Walsingham) (Lepidoptera: Tortricidae), when traps were not regularly maintained throughout the flight season (Sweeney et al. 1990). Captured moths will decay if traps are deployed for long periods, and this can affect moth orientation to the trap (Sanders 1986b) and make the sample difficult to count. Non-saturating traps are more expensive than sticky traps but can be reused in subsequent seasons to reduce monitoring costs. However, pheromone contamination of the plastic nonsaturating traps can persist across seasons (Grant 1991) and influence subsequent trap capture.

Monitoring for population assessment implies that the number of insects captured in pheromonebaited traps reflects the actual population density of the target insect. This relationship is often established by relating the number of moths captured in pheromone-baited traps to estimates of population density of other life stages, or to defoliation caused by larval feeding. If this relationship is robust, pheromone-based monitoring can replace more costly sampling techniques such as foliage samples, or samples of immature stages (Sanders 1988). These types of relationships have been established for forest defoliators in Canada by sampling populations over long periods of time (Sanders 1988) or targeting populations of differing densities over a condensed period (Shepherd et al. 1985; Sweeney et al. 1990; Evenden et al. 1995a).

There has been variable success in generating these relationships using sites at different population densities over short sample durations (two years). Trap capture of western hemlock looper moths in $10 \mu \mathrm{g}$-baited non-saturating traps was predictive of the number of eggs extracted from $100 \mathrm{~g}$ of arboreal lichen in the subsequent generation. This relationship was best at the beginning of the flight season (Evenden et al. 1995a). Western spruce budworm season-long capture was not correlated to the number of larvae sampled from mid-crown branch tip samples of 50 trees at the same sites. However, capture of western spruce budworm moths per basal area or foliage biomass per ha significantly predicted larval density in the subsequent generation (Sweeney et al. 1990). These results indicate that pheromone-baited traps are likely drawing in male moths from a distance far beyond where larval sampling was conducted. Trap capture of Douglas-fir tussock moths in saturating sticky traps baited with various pheromone doses did not predict numbers of egg masses or defoliation damage in the following generation, but trap capture of more than 25 moths was indicative of incipient outbreaks (Shepherd et al. 1985).

There is a curvilinear relationship between the number of male forest tent caterpillar moths, Malacosoma disstria Hübner (Lepidoptera: Lasiocampidae), captured in non-saturating Unitraps and immature stages sampled within the same generation. Fewer male moths were captured in traps positioned in high-density sites than sites with intermediate densities (Jones et al. 2009). At extremely high population densities, it is possible that male moth orientation to pheromone is disrupted due to ambient levels of pheromone produced by the thousands of females in the stand or that males use cues other than olfaction to locate mates (Hagaman and Cardé 1984). It is also possible that characteristics of the defoliated stand alter the release dynamics of pheromone from the trap, which influence male moth response to the lure. Capture of male spruce 
budworm moths in pheromone-baited traps was variably related to larval density when sampled in many plots with different densities. However, moth capture was highly related to larval density when comparisons were made over time in a 21-year trapping study in the same location (Sanders 1988). This research resulted in the development of a season-long threshold capture of 50-100 moths to trigger more intensive larval sampling in an operational monitoring system (Sanders 1988).

The use of sex pheromone-baited traps for accurate measurement of population levels of forest defoliators has met with variable success. There is still work to do in developing the relationships between trap counts of adults and subsequent larval stages and ultimately, damage. These efforts may be assisted by incorporating additional information such as environmental conditions, parasitism levels and moth population quality into models relating moth trap capture to densities of immature stages and defoliation estimates. Information on moth population quality can be obtained from specimens captured in pheromone-baited traps. Measurement of moth size and assessment of disease status by moth dissection (Jones and Evenden 2008) can provide an indication of the stage of the outbreak cycle.

Monitoring for population quality: Pheromone trapping can also be used for ecological applications to better understand the population dynamics of forest defoliators. The effect of timing of adult emergence, geographic region, and population density on moth quality of the forest tent caterpillar and large aspen tortrix, Choristoneura conflictana Walker (Lepidoptera: Tortricidae) were studied (Jones and Evenden 2008) using moths captured in a combined pheromone-based monitoring system that targeted both species simultaneously (Jones et al. 2009). Moth quality was measured using wing area and microsporidian infection level of captured individuals. Wing area decreases over the flight season in forest tent caterpillar but not in large aspen tortrix moths captured in pheromone-baited traps (Jones and Evenden 2008). Comparisons of moths captured in different regions reveals that microsporidian infection of male forest tent caterpillar moths varies greatly with geographic region but not with population density. It is unclear whether defoliators with sublethal infections are as responsive to pheromone cues and therefore as likely to be captured in pheromone-baited traps as healthy moths. Dispersal of female but not male spruce budworm moths in the field was affected by infection with microsporidia (Eveleigh et al. 2007). Similarly, infected and uninfected male spruce budworm moths flew for similar durations in wind tunnel bioassays (Sanders and Wilson 1990). However, the proportion of male western spruce budworm that exhibit pheromonemediated behaviours in the wind tunnel was negatively correlated with the microsporidian load of male moths (Sweeney and McLean 1987). This reduction in pheromone-mediated behaviours was not the result of reduced sensitivity to pheromone, as electroantennogram readings from the antennae of infected and uninfected males were similar (Sweeney and McLean 1987). These types of data could be incorporated into models of population assessment and provide managers with a better understanding of the stage of the sampled population in the cyclical population dynamics of forest defoliators.

The mating status of male moths captured in pheromone-baited traps can also be determined in some species (Bergh and Seabrook 1986a). Dissection of male spruce budworm moths that were freshly caught in pheromone-baited sticky traps can be reliably used to determine recent mating activity by the colour of the secretion in section 7 of the ejaculatory duct primary simplex (Bergh and Seabrook 1986b). Using this tool, the proportion of mated males in the population can be tracked throughout the flight season or in different regions of the forest canopy (Bergh et al. 1988). This tool could be adopted for studies of Allee effects on the population dynamics of the spruce budworm.

\section{Mating disruption to reduce populations of forest defoliators}

Some of the physical characteristics of forests and the biological attributes of forest defoliators predispose this system to effective management by mating disruption as part of an IPM approach. Pheromone-based mating disruption works best when pheromone is applied over a large area in an attempt to provide "area-wide management" (Witzgall et al. 2010) and reduce damage at the edge of the treated area thought to result from immigration of gravid females into the treatment 
zone (Gut et al. 2004). Treatment of large areas of forested lands with aerially applied pheromone should be a good approach to achieve area-wide management, but penetration of the tree canopy to provide an even distribution of pheromone is problematic. Evenness of the forest canopy will promote better control by mating disruption because foliage will trap the pheromone within the stand and minimise the dissipation effect of the wind. The waxiness of conifer foliage may also promote the adherence of lipophilic pheromone molecules to the surface of the leaves where they can be adsorbed and re-released (Gut et al. 2004). The usefulness of mating disruption for control of forest defoliators may be limited by the fact that efficacy of pheromone-based control generally declines with increased population density (Gut et al. 2004).

Biological attributes that predispose some forest defoliators to control by mating disruption include: (1) a univoltine life cycle that results in a short and well-defined period of adult activity that can be targeted by pheromone application; (2) a restricted host range; and (3) limited dispersal capacity of females.

Spruce budworm: Thirty years of field and laboratory research conducted primarily in Canada on the feasibility of control of the spruce budworm by pheromone-based mating disruption led to the recent Canadian registration of Disrupt SBW microflakes ${ }^{\circledR}$ (Hercon Environmental, Emigsville, Pennsylvania, United States of America), a pheromone formulation that is applied aerially to affected forest stands. Laboratory and field studies on the development of pheromone-based mating disruption of spruce budworm conducted between 1974 and 2008 have recently been reviewed (Rhainds et al. 2012). Although most of the field studies reviewed demonstrated a reduction of mate-finding behaviour in pheromone-treated plots, there was rarely a difference in the number of egg masses sampled between control and treated areas. This potentially could be the result of the movement of gravid females into the treated area (Rhainds et al. 2012). Several studies illustrate that female spruce budworm moths are able to detect their own pheromone signal and increase their activity (Palaniswamy and Seabrook 1978) and flight behaviours (Sanders 1987) in the presence of sex pheromone. Detection of high quantities of female-produced pheromones in heavily infested stands may be an adaptive cue that promotes female dispersal away from defoliated stands (Sanders 1987). The high dispersal capacity of female spruce budworm moths (Greenbank et al. 1980) has been cited as a constraint that may limit the effectiveness of mating disruption to control spruce budworm (Rhainds et al. 2012).

Limited success of early studies to develop the mating disruption technique to control spruce budworm led to a switch in research focus to understand the mechanisms by which pheromone interferes with mate-finding behaviour (Sanders 1982). There are several mechanisms to explain how pheromone-based mating disruption interferes with mate-finding behaviour in moth pests (Bartell 1982; Cardé 1990). These include: (1) false-trail-following, when male moths orient to synthetic sources of sex pheromone in a treated area instead of to females; (2) neurophysiological effects that result in desensitisation to the pheromone signal as a result of adaptation of antennal receptors or habituation of the central nervous system processing of the pheromone signal; and (3) camouflage of the female-produced pheromone plumes due to a physical masking by the synthetic pheromone in the environment. Careful experimentation of male spruce budworm moth behaviour in pheromone-mediated wind tunnels led to the conclusion that several mechanisms probably reduce mate-finding behaviour in pheromone-treated areas (Sanders 1995). Exposure to a concentration of $20 \mathrm{ng} / \mathrm{m}^{3}$ of pheromone caused habituation of male moths and reduced their ability to orient to females (Sanders 1996). False-trail-following is an important mechanism in mating disruption of spruce budworm moths, as disruption is greatest when the most attractive ratio of the two pheromone components is deployed (Sanders 1981). False-trail-following to synthetic pheromone plumes occurs repeatedly in wind tunnels treated with discrete pheromone plumes but did not completely prevent orientation to femaleproduced plumes (Sanders 1995).

Mating disruption of spruce budworm will be most beneficial as part of an IPM strategy with effective pheromone-based monitoring to warn forest managers of impending outbreaks (Sanders 1988) and additional control tactics such as aerial application of Bacillus thuringiensis subspecies kurstaki (Bacteria) at moderate to high budworm 
densities (Bauce et al. 2004). Mating disruption will be most effective when incorporated for early intervention instead of a response to ongoing levels of measurable defoliation (Rhainds et al. 2012). This approach is similar to the highly successful "slow-the-spread" mating disruption programme for gypsy moth in the United States of America (Reardon et al. 1998). Mating disruption is expected to work best at low population densities when non-pheromone-mediated chance encounters between males and females should be low (Gut et al. 2004). There is evidence that the efficacy of mating disruption declines with increased population density of spruce budworm moths, as mating of caged moth pairs increases with population density in a pheromone-treated environment but not in clean air (Palaniswamy et al. 1982). This suggests that not only does mating disruption break down at high population densities, it may actually promote further mating at high densities. False-trail-following is the mating disruption mechanism that is most affected by high population densities and the mechanism most commonly cited to interfere with mating behaviour of the spruce budworm (Rhainds et al. 2012).

Male sensitivity to pheromone is a physiological characteristic that varies among moth species and has been linked to the susceptibility of moths to control by pheromone-based mating disruption (Gut et al. 2004). Male moths that exhibit a broad dose response to pheromone with no upper threshold are often more difficult to disrupt than species with a narrowly defined dose response that are arrested by high pheromone doses (Gut et al. 2004). Spruce budworm males orient to a wide range of pheromone doses in a wind tunnel and show no decrease in response to the highest dose tested (Sanders 1990). Males of the congener Choristoneura rosaceana Harris (Lepidoptera: Tortricidae), an important tree fruit pest, are also attracted to a wide range of pheromone doses (Gut et al. 2004). This species has also proven to be difficult to control by pheromone-based mating disruption (Lawson et al. 1996). Choristoneura rosaceana exhibits long-lasting adaptation of antennal sensory neurons in pheromone-treated atmospheres (Stelinski et al. 2003). This may shield the central nervous system and prevent longer-lasting habituation of pheromone processing, which allows for rapid recovery of pheromone responsiveness in clean air (Evenden et al. 2000).
The chemical characteristics of the sex pheromone of each species can also affect the efficacy of pheromone-based mating disruption (Gut et al. 2004). The sex pheromone of the spruce budworm, like many other tortricine moths, consists of a blend of 14-carbon straight chain hydrocarbons with aldehyde, alcohol, or acetate functional groups and an internal double bond in the carbon-11 position (Silk et al. 1980). The blend used in commercial formulations consists of a 95:5 ratio of $(E)$ :(Z)-11tetradecenal. Each of these pheromone components has a molecular weight of 210.4 , which corresponds to a rapid evaporation rate compared with pheromone products with longer chain lengths. Pheromone formulations with low molecular weight pheromone components will have a limited period of efficacy in the field. Wiesner et al. (1980) measured atmospheric concentration of pheromone in plots treated with hollow fiber dispensers releasing spruce budworm sex pheromone. Initial measurements of $9 \mathrm{ng} / \mathrm{m}^{3}$ decreased to $<2 \mathrm{ng} / \mathrm{m}^{3}$ over a two-day period (Wiesner et al. 1980). It is important to note that even the initial release rate measured would not be adequate to habituate male spruce budworm moths (Sanders 1996).

Pheromone released from mating disruption formulations is in the vapour state but can condense and be adsorbed onto solid surfaces such as tree foliage under ordinary environmental conditions (Gut et al. 2004). The molecular weight and functional groups of the pheromone molecule will dictate the likelihood that pheromone adherence to foliage will occur. The "stickiness" of the pheromone molecule increases with carbon chain length and oxygenation of the hydrocarbons. Although partitioning of the pheromone from the vapour phase onto a solid surface can occur with pheromone molecules with $>200 \mathrm{MW}$ (Gut et al. 2004), this effect would be expected to be greater for gypsy moth (19 carbons) and Douglas-fir tussock moth pheromones (21 carbons). Treatment with pheromones that are likely to adhere to the foliage can result in a buildup of pheromone concentration in the canopy and contribute to successful mating disruption (Gut et al. 2004).

Limitations to pheromone-based control of spruce budworm with mating disruption include: (1) high dispersal capacity of gravid female moths that may be influenced by perception of pheromone; (2) increased mating rates at high density in pheromone-treated air; (3) a broad dose 
response to pheromone by male moths; and (4) the physical properties of the relatively low molecular weight pheromone components.

Douglas-fir tussock moth: The use of pheromone-based mating disruption has also been studied for the Douglas-fir tussock moth, a defoliator of Douglas-fir, Pseudotsuga menziesii (Mirbel) Franco, true firs, Abies Miller, and pines, Pinus Linnaeus (Pinaceae) in western United States of America and British Columbia (Furniss and Carolin 1977). The Douglas-fir tussock moth is a good species to target with pheromone-based mating disruption as the females are wingless and cannot disperse (Furniss and Carolin 1977). The sex pheromone produced by female moths consists of a blend of 21-carbon ketones (Gries et al. 1997), but only the main component, $(Z)-6$-heneicosen11 -one, is used in commercial applications. The long chain length of this compound prevents problems associated with premature loss of pheromone from dispensers (Sower et al. 1983). Pheromonemediated mating disruption interferes with moth reproduction at both low (Sower et al. 1979) and high (Sower et al. 1983) population densities. Although pheromone treatment reduced the number of egg masses produced in treated areas, it did not affect the rate of parasitism by three common egg parasitoids of the Douglas-fir tussock moth (Cook et al. 2005). Pheromone-mediated mating disruption of Douglas-fir tussock moth is compatible with naturally occurring mortality factors.

A series of experiments conducted in the early 1990s in southern British Columbia assessed a PVC bead pheromone formulation as a mating disruptant of the Douglas-fir tussock moth. Application of the high dose of $72 \mathrm{~g} / \mathrm{ha}$ of pheromone applied from the air completely interfered with male moth orientation to feral females, and no egg masses were found in treated plots. Ground application also significantly reduced mating and egg production but did not eliminate it (Hulme and Gray 1994). The PVC beads continued to emit pheromone that impacted male moth behaviour up to two years after treatment, highlighting the long-lasting effect of the 21-carbon pheromone, (Z)-6-heneicosen-11-one (Gray and Hulme 1995). Later studies showed that the application rate of pheromone could be reduced by at least four-fold to $18 \mathrm{~g} / \mathrm{ha}$ and still maintain 100\% mating disruption (Hulme and Gray 1996).

Pheromones are mostly used for monitoring in management programmes for the Douglas-fir tussock moth, and a nuclear polyhedrosis virus is used for control (Shepherd 1994). Effective mating disruption at low pheromone application rates (Hulme and Gray 1996) and long-lasting treatment effects (Gray and Hulme 1995) suggest that pheromone-mediated mating disruption may be an economical component in an IPM strategy for the Douglas-fir tussock moth. The economics of commercialisation of a mating disruption formulation for the Douglas-fir tussock moth may be improved by also using the same compound to disrupt mating of other tussock moth species (Grant 1978; Grant and Frech 1980).

\section{Use of semiochemicals in management of bark and ambrosia beetles}

The use of semiochemicals by bark and ambrosia beetles (Coleoptera: Curculionidae: Scolytinae) is fundamentally different to the way in which they are used in the Lepidoptera (Borden 1993). Bark and ambrosia beetles use a suite of semiochemicals to mediate orientation to hosts, aggregation and mass attack of hosts, and termination of mass attack (Borden et al. 1987a). Other members of the subcortical community, such as competitors and entomophagous insects, can also generate and respond to their own intraspecific signals or exploit interspecific semiochemicals in the environment (Borden 1989). The volatile profile released by living trees changes after attack by bark beetles (Lusebrink et al. 2011).

Exploitation of semiochemicals to manipulate bark and ambrosia beetle behaviour has been the focus of applied research and the goal of semiochemical-based management of these beetle pests in Canada (Borden 1989). Most research has focussed on aggressive tree-killing bark beetles (Borden 1992) that are pests of living stands and on ambrosia beetles that attack harvested trees (Borden and Lindgren 1989). Control strategies include manipulation of semiochemical-based mass attack, exploitation of repellent semiochemicals such as antiaggregation pheromones and non-host volatiles to disrupt bark beetle orientation away from host trees, and enhancement of natural control (Borden and Lindgren 1989). For each of these management strategies, there are various tactics that have been developed (Fig. 3), some of which have been 
Fig. 3. Semiochemical-based management of bark and ambrosia beetles based on Borden (1989). Letters embedded in arrows indicate whether the tactics and tools are in the $(\mathrm{O})$ operational, (R) research, or (I) innovation stage of the research-application continuum in Canada. *Monosodium methanearsonate (MSMA) was used operationally between the mid-1980s and 2004 but is no longer registered in Canada.

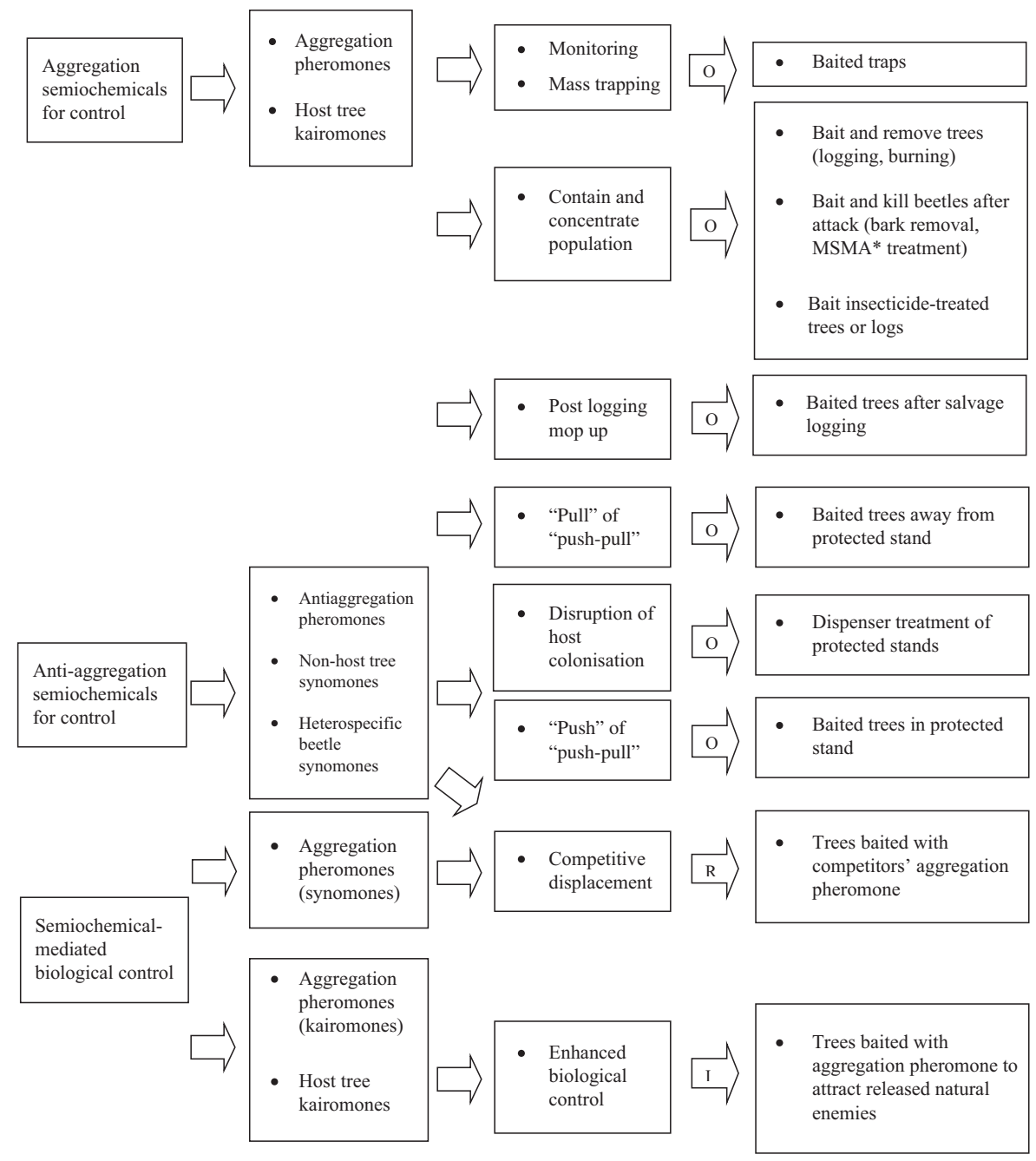

applied to manage different bark beetle species under various stand conditions to address a range of stakeholder priorities in Canada.

\section{Host colonisation semiochemicals for monitoring and control of bark and ambrosia beetles}

Monitoring: A major contribution of Canadian research to beetle management was the design of a multiple-funnel trap (Lindgren 1983) that was later referred to as the Lindgren funnel trap. This trap features a series of funnels that provide a vertical silhouette to which dispensers of attractive semiochemicals can be fastened. Attracted beetles flying to the trap hit the angled sides of the funnels and are collected in a container fastened at the bottom of the series of funnels. This trap replaced more labour-intensive traps for bark and ambrosia beetles that used sticky surfaces for beetle capture (McLean and Borden 1979). Processing time of collected beetles is reduced over earlier trap types, and the funnels collapse for easy storage and transport of the traps (Lindgren 1983). 
The Lindgren trap provides a dark, vertical silhouette with similar spectral reflectance properties to that of conifer tree hosts (Campbell and Borden 2005), which is an important component of host location for coniferophagous bark beetles (Campbell and Borden 2006). Attraction to aggregation pheromone-baited Lindgren funnel traps was reduced for three different species of bark beetles when the black funnels were replaced with white ones, suggesting that visual and olfactory cues are integrated in the host location process in bark beetles (Campbell and Borden 2006). Lindgren funnel traps have been widely adopted for research and management of many bark and ambrosia beetle species even though theoretical modelling exercises suggest that other trap types may be more efficient at beetle capture (Safranyik et al. 2004). In empirical studies, the Lindgren funnel trap was more effective at capture of the striped ambrosia beetle Trypodendron lineatum (Olivier) (Coleoptera: Curculionidae: Scolytinae) than similarly baited drain pipe traps and slot traps in experiments conducted in British Columbia (McLean et al. 1987).

Efficacious monitoring using semiochemicalbaited traps also depends on development of an attractive semiochemical lure. In the case of bark beetles, development of semiochemical lures goes beyond identification of aggregation pheromones (Table 1) because, depending on the bark beetle species, kairomones released by host trees can be attractive alone or synergise beetle response to aggregation pheromone (Pureswaran and Borden 2005). Early investigations in British Columbia tested the attractiveness of the mountain pine beetle female-released aggregation pheromone, trans-verbenol, and the male-released aggregation pheromone, exo-brevicomin, in conjunction with six monoterpenes known to be released from the principal host of the mountain pine beetle, lodgepole pine, Pinus contorta Douglas (Pinaceae) (Conn et al. 1983). These studies formed the basis for the development of commercial lures used to bait Lindgren funnel traps that released a combination of the two aggregation pheromones and the host kairomone myrcene (Borden et al. 1986). Lindgren funnel traps baited with this mixture of semiochemicals are used principally to monitor beetle emergence and the length of the flight period (Maclauchlan and Brooks 1998). This information can be used to restrict movement of infested logs during emergence and flight periods of the beetle (Borden and Lacey 1985).

Attraction of the mountain pine beetle is dependent on the dose of the pheromone (Miller et al. 2005) and the kairomone myrcene (Borden et al. 1987a). The male aggregation pheromone, exo-brevicomin, is attractive at low doses and inhibitory at high doses (Borden et al. 1987a; Miller et al. 2005). Interestingly, the shape of the dose response curve to trans-verbenol is dependent on the population density of beetles in the stand. At high population densities, the number of mountain pine beetles attracted to the femalereleased aggregation pheromone increased directly with pheromone release rate; at low population densities, response to the highest doses tested decreased (Miller et al. 2005). Later research showed that the addition of another host volatile, terpinolene, to the mixture of aggregation pheromones and myrcene increased the attractiveness of the lure to mountain pine beetles and increased the female:male sex ratio of captured beetles, suggesting that baited traps might be developed for mass trapping (Borden et al. 2008). With the expansion of the range of the mountain pine beetle into northern Alberta, semiochemical traps have been used to detect the presence of the beetle at the leading edge of the expansion (Table 2). Semiochemical-baited traps captured beetles released within a 500-m radius of the trap (Barclay et al. 1998), and therefore trap capture is a good indicator of presence of beetles in the direct trapping area.

Mass trapping: The best example of a successful, operational semiochemical-based mass-trapping programme in Canada is that designed to control the ambrosia beetles, Trypodendrum lineatum, Gnathotrichus sulcatus (LeConte), and Gnathotrichus retusus (LeConte) (Coleoptera: Curculionidae: Scolytinae) (Borden et al. 2001), which are pests of felled timber and freshly milled green lumber in British Columbia and the western United States of America (Borden 1990). Beetles feed on ambrosia fungus and create tunnels stained by their fungal associates that lead to degradation of the lumber. Because of the different phenologies of the three main ambrosia beetle species, felled trees at sawmills and dryland sorting areas are vulnerable to attack for an eightmonth period each year (Borden 1990). 
Table 2. Semiochemical tactics used to manage the range expansion of mountain pine beetle into Alberta, Canada, 2007-2012 (Alberta Environment and Sustainable Resource Development, unpublished data).

\begin{tabular}{|c|c|c|c|c|c|}
\hline Tactic & Tool & $\begin{array}{c}\text { Number of sites } \\
\text { treated in Alberta by } \\
\text { AESRD* }\end{array}$ & $\begin{array}{l}\text { Number } \\
\text { deployed in } \\
\text { Alberta }\end{array}$ & $\begin{array}{l}\text { Estimated cost (Canadian } \\
\text { \$) of pheromones used in } \\
\text { treatment }\end{array}$ & $\begin{array}{l}\text { Estimated total cost } \\
\text { (Canadian \$) of } \\
\text { treatment }\end{array}$ \\
\hline Monitoring & $\begin{array}{r}\text { Funnel } \\
\text { traps }\end{array}$ & 74 & 148 & $\begin{array}{l}\$ 17527.64 \text { (including } \\
\text { trap + stand) }\end{array}$ & $\$ 150000$ \\
\hline $\begin{array}{l}\text { Monitoring + tree } \\
\text { removal }\end{array}$ & $\begin{array}{l}\text { Tree } \\
\text { baits }\end{array}$ & 2795 & 8386 & $\$ 35636.25$ & $\$ 1800000$ \\
\hline
\end{tabular}

Note: *Alberta Environment and Sustainable Resource Development.

Research that led to the development of semiochemical-based mass trapping of ambrosia beetles was mainly conducted at Simon Fraser University and the University of British Columbia (British Columbia, Canada). Research began in the late 1960s with the identification of the aggregation pheromones of the three ambrosia beetle pests (Table 1). Further research showed that $T$. lineatum only responded to the $(+)$ enantiomer (Borden et al. 1980c) of the identified female-produced aggregation pheromone, lineatin (MacConnell et al. 1977). As T. lineatum response to $(+)$ enantiomer of lineatin is not influenced by the (-) enantiomer (Borden et al. 1980c), a cheaper racemic mixture of the two enantiomers could be developed operationally for mass trapping.

The aggregation pheromone of G. sulcatus was identified as the male-produced sulcatol (Byrne et al. 1974). Like lineatin, sulcatol is an optically active compound that has two enatiomers: $S$-(+)-sulcatol and $R$-(-)-sulcatol. The finding that the enatiomers of sulcatol act synergistically to attract G. sulcatus was published in Science in 1976 (Borden et al. 1976). Interestingly, G. retusus is also attracted to $\mathrm{S}-(+)$-sulcatol (retusol) but species specificity of the chemical communication channel is maintained by arrestment of G. retusus to R-(-)-sulcatol (Borden et al. 1980b). Further, racemic mixtures of lineatin and sulcatol negatively influence response of T. lineatum and G. sulcatus (Shore and McLean 1983). Beyond uncovering the interesting interspecific chemical communication among species of sympatric ambrosia beetles (Shore and McLean 1983), this research led to the practical finding that purified S-(+)-sulcatol is required for semiochemical-based management of G. retusus, and separately baited traps are required for T. lineatum and G. sulcatus. In addition to aggregation pheromones, ambrosia beetles respond to host-produced kairomones, particularly ethanol (Moeck 1970). Ethanol and $\alpha$-pinene are hostproduced kairomones that attract ambrosia beetles to suitable hosts and also synergise response to aggregation pheromone (McLean and Borden 1977; Borden et al. 1980a). The unravelling of the chemical ecology of these three species of ambrosia beetles along with the invention of the Lindgren funnel trap (Lindgren 1983), paved the way for operational studies of mass trapping for population control of ambrosia beetles in British Columbia.

Operational-level research was conducted between 1976 and 1981 that targeted control of G. sulcatus (McLean and Borden 1979) and T. lineatum (Lindgren and Borden 1983) by semiochemical-based mass trapping in conjunction with manipulation of stored log inventories. Traps are positioned to lure beetles away from the stored wood. As T. lineatum overwinters in the duff of the forest floor, traps are placed around the timber to be protected with the hope of intercepting beetles orienting to harvested logs. The Gnathotricus species overwinter in felled timber or woody debris and upon emergence need to be lured away from the stored wood. The success of mass trapping efforts was measured through overwintering samples of $T$. lineatum in the duff (Lindgren and Borden 1983) and mark-recapture studies of both T. lineatum and G. sulcatus (Shore and McLean 1988). As of 1990, there were more than 55 operational trapping programmes for ambrosia beetle in British Columbia and the western United States of America (Lindgren 1990) 
with gross sales of $\sim \$ 400000$ Canadian (E. Stokkink, Woodstock Management Inc., Nanaimo, British Columbia, Canada, personal communication) and an estimated benefit/cost ratio of 5:1 (Lindgren and Fraser 1994). Between 1995 and 2008, semiochemical-based management of ambrosia beetle on coastal Vancouver Island was steady between 20-35 sites with annual sales at $\sim$ \$150000-200000 Canadian. In 2008, the economic downturn forced operators to reduce their stored log inventory, amalgamate sorting areas, and reduce spending on pest management. This led to a reduction in the number of operational mass trapping sites on Vancouver Island since 2008 to eight sites (E. Stokkink, Woodstock Management Inc., personal communication).

Containment and concentration: One of the most successful uses of semiochemicals in IPM against bark beetles is for the containment and concentration of populations, followed by tree removal or induction of beetle mortality (Fig. 3). This tactic exploits beetle aggregation pheromones and host tree kairomones to direct beetle attack to baited trees (Borden 1992). This serves to intensify and direct the beetle attack into an area that can be easily reached after attack to remove the beetles. The approach also provides forest managers with much needed time in which to implement beetle removal from the stand before the emergence of the next generation of beetles, 10-11 months later for univoltine species (Borden and Lacey 1985). In Canada, this tactic has been used against aggressive tree-killing bark beetles such as the mountain pine beetle, the Douglas-fir beetle, Dendroctonus pseudotsugae Hopkins, and the spruce beetle, Dendroctonus rufipennis Kirby (Coleoptera: Curculionidae: Scolytinae) (Borden 1993). Canadian research on this semiochemical-mediated IPM tactic has mostly focussed on the mountain pine beetle, the spruce beetle, and the western balsam bark beetle, Dryocetes confuses Swaine (Coleoptera: Curculionidae: Scolytinae).

Early studies to assess the feasibility of the containment and concentration tactic against the mountain pine beetle focussed on the most appropriate mixture of semiochemicals to use in tree baits (Borden et al. 1983c). As in the studies examining the attractiveness of various semiochemicals for the development of trap lures (Conn et al. 1983), the most attractive tree baits released the two mountain pine beetle aggregation pheromones trans-verbenol and exo-brevicomin and the host kairomone myrcene (Borden et al. 1983c). Although early research suggested that the incorporation of myrcene would improve tree baits releasing aggregation pheromones alone (Borden et al. 1983c), later research showed that tree baits could be simplified to release only the aggregation pheromones without loss of efficacy (Borden et al. 1993). Currently available baits used for tree baiting contain only the two mountain pine beetle aggregation pheromones.

The tactic of semiochemical-based containment and concentration of mountain pine beetle infestations was designed following the protocol of Pitman (1973) by baiting one lodgepole pine tree every $50 \mathrm{~m}$ in the treated areas (4 baits/ha) (Borden 1992). These studies were assessed by comparing the ratio of the number of attacked trees during the year of tree baiting to that of previous years (green: red attack) in the treated and control plots (Borden et al. 1983b, 1983c). Higher green: red attack ratios in the baited than control plots indicated containment of the beetle population either through restriction of dispersal out of the plot or attraction of beetles into the baited area (Borden 1992). Concentration of beetle attack in response to semiochemical-based tree baiting was tested by dividing baited plots into concentric zones around a heavily infested plot centre (Gray and Borden 1989). In the treated plots, the central zone of the plot contained nine baited trees at 50-m intervals. A middle zone consisted of a 50-m buffer around the perimeter of the central zone, and the exterior zone was a 100-m buffer around the middle zone. In baited plots, fresh beetle attack was concentrated within the central zone compared with control plots, in which the highest green: red ratio occurred in the middle zone due to beetle dispersal (Gray and Borden 1989). The development of an attackintensification ratio that incorporated the tree diameter and attack density in green: red attacked trees provided a metric that could be used in operational settings in the absence of unbaited control plots (Gray and Borden 1989).

Operational use of tree baiting involves removal of the attacked trees before the next generation of beetles emerges (Fig. 3). This can be achieved by removal of the baited, attacked trees 
through sanitation-salvage logging after attack in the 11-month period before emergence of the next generation (Borden and Lacey 1985). Sanitation logging of infested trees is followed by debarking of harvested trees to kill the developing brood. The year following removal of the attacked pines, tree baits can be used to "mop-up" the residual mountain pine beetle population (Borden et al. 1983a). If the infested area is too small to warrant salvage logging of the stand, tree baiting can still be used to concentrate beetle attack, followed by control of beetles in the baited trees by felling and burning, debarking, or insecticide application (Borden 1990). Felling and burning is commonly used in British Columbia (Borden 1990) and was adopted in Alberta, Canada (Table 2), where the invasion of large numbers of beetles into the province has resulted in adoption of semiochemical-based containment strategies (Table 2). When felling and burning of the attacked baited trees cannot be achieved due to the terrain or risk of wild fire, insecticide application to felled (Fuchs and Borden 1985) or standing trees (Maclauchlan et al. 1988) after attack can eliminate beetle populations in baited trees. The arsenical compound monosodium methanearsonate (MSMA) applied to the base of attacked trees through an axe frill (cut) in the bark is translocated up the tree. MSMA treatment kills beetles through direct poisoning, by indirectly decreasing phloem moisture and making the tree susceptible to fungal invasion (Maclauchlan et al. 1988). Re-registration of MSMA was not pursued in 2005 due to findings of Canadian wild life research that showed treated trees that remain on the landscape change the foraging behaviour of insectivorous woodpeckers (Morrissey et al. 2008) and expose them to harmful levels of arsenic (Morrissey et al. 2007).

Semiochemical-based containment and concentration have also been developed for other aggressive bark beetles as the result of Canadian research efforts. Tree baiting with the aggregation pheromone frontalin (Gries et al. 1988) and the host kairomone $\alpha$-pinene has been used to contain and concentrate spruce beetle populations in living (Shore et al. 1990) or dead (Gray et al. 1990) spruce "trap trees". Tree baiting at 50-m intervals concentrated spruce beetle attack on standing spruce trees in semiochemical-baited plots compared with control plots under epidemic population densities (Shore et al. 1990).
Although baited trees did not receive more attacks than unbaited trees within treated plots, the overall concentration of attack was four times greater in treated versus control plots (Shore et al. 1990). At endemic population densities, another approach to semiochemical-based management of spruce beetle is to bait living trees that are capable of defending themselves against the attracted beetles to avoid a population build-up in wind-thrown trees (Dyer and Safranyik 1977). One hundred randomly distributed spruce trees were baited in a 766-ha stand. Although all of the baited trees and some of the adjacent unbaited trees were attacked by spruce beetle, $95 \%$ of the attacks in the stand occurred on wind-thrown trees, suggesting that this approach is limited to stands with minimal downed host material (Dyer and Safranyik 1977). Later research on semiochemical-based management of the spruce beetle showed that the incorporation of other beetle-produced semiochemicals, including 4-methylene-6,6-dimethylbicyclo[3,1,1]hept-2-ene (verbenene) and 1-methyl-2-cyclohexen-1-ol (MCOL), into tree baits was variably effective depending on the geographic location of the experiment (Borden et al. 1996).

Semiochemical-based containment and concentration of the western balsam bark beetle in subalpine fir, Abies lasiocarpa (Hooker) Nuttall (Pinaceae), stands can be achieved with tree baits releasing a racemic mixture of $( \pm)$-exo-brevicomin (Stock et al. 1994; Jeans-Williams and Borden 2006). Tree baiting experiments in 16-ha plots showed that western balsam bark beetle populations could be concentrated within $10 \mathrm{~m}$ of baited trees even at epidemic population densities (Stock et al. 1994). Concentration of beetle attack was better when two trees instead of one were baited per spot in one experiment (Stock et al. 1994) but not in another (Maclauchlan et al. 2003). Semiochemicalmediated response of the western balsam bark beetle is enantiospecific (Camacho et al. 1993). Trees baited with a 9:1 blend of (+)-exo-brevicomin to $(+)$-endo-brevicomin were more heavily attacked than trees baited with $( \pm)$-exo-brevicomin (Camacho and Borden 1994), suggesting that enantiospecific tree baits may be more effective at concentrating beetle populations. However, later experiments that compared the ability of the standard bait and enantiospecific baits at different release rates to contain and concentrate western 
balsam bark beetle populations showed no difference in efficacy (Jeans-Williams and Borden 2006). Therefore, the cheaper racemic mixture of $( \pm)$-exobrevicomin is an effective tree bait that can be used to manage the western balsam bark beetle for timber or wildlife values (Maclauchlan et al. 2003). Sympatric distribution of the western balsam bark beetle and the spruce beetle and lack of overlapping pheromone components allows for tree baiting targeting both species in stands of spruce and subalpine fir (Greenwood and Borden 2000). In 9-ha plots treated with tree baits of both species, semiochemical treatment was successful at concentrating and containing beetle activity of both species. Green to red attack ratios on both species of trees were greatest in the baited central zone of plots compared with the unbaited peripheral zones, suggesting that populations of both bark beetle species can be simultaneously manipulated (Greenwood and Borden 2000).

Containment and concentration of bark beetle populations in trees baited with semiochemicals followed by beetle removal (Fig. 3) has become a mainstay of forest pest management. However, a comparison of semiochemical techniques to remove Douglas-fir beetle from the population suggested that more beetles could be removed with semiochemical-baited traps than with baited living or trap trees (Laidlaw et al. 2003). Baited trees became saturated with beetles within the first 20-30 days of beetle flight activity, whereas traps continued to remove beetles from the population throughout the flight duration (Laidlaw et al. 2003). This finding suggests that mass trapping of bark beetles in limited and particularly environmentally sensitive areas may be a viable alternative to tree baiting that involves the use of chemicals or tree removal (Borden 1993).

\section{Antiaggregation semiochemicals for control of bark and ambrosia beetles}

Bark and ambrosia beetles also use semiochemical messages to interrupt or avoid aggregation and host colonisation processes. These semiochemicals can include antiaggregation pheromones or heterospecific synomones that regulate the density of the mass attack by deterring late-arriving beetles from attacking a "full" tree of conspecifics or heterospecifics, respectively (Borden 1997). In addition, most coniferophagous bark (Huber et al. 2000) and ambrosia (Borden et al. 2001) beetles are able to sense semiochemicals emitted from non-host angiosperm trees, which is adaptive as beetles can avoid orientation to non-hosts. There is understandably great interest in the exploitation of antiaggregation behaviour of bark beetles to disrupt mass attack and avoid host tree death (Borden 1997). This has led to extensive applied research on the identification and use of these compounds in semiochemical-based management of bark and ambrosia beetles.

Antiaggregation pheromones: Most Canadian research on antiaggregation pheromones has focussed on verbenone (4,6,6-trimethylbicyclo [3,1,1]-hetp-3-en-2-one) as it elicits an antiaggregation response by several species of bark beetle and other phloeophagous insects (Lindgren and Miller 2002). When tested in Lindgren funnel traps baited with aggregation pheromones, verbenone significantly reduced trap capture of the mountain pine beetle, and two secondary bark beetles that attack pine, the pine engraver, Ips pini Say and I. latidens (LeConte) (Coleoptera: Curculionidae: Scolytinae) (Miller et al. 1995). In the mountain pine beetle, verbenone is produced by autooxidation (Hunt et al. 1989) and oxidation of verbenol by microbial associates of the female beetles (Hunt and Borden 1990) late in the colonisation process (Pureswaran et al. 2001). Therefore, this compound may better be described as a kairomone that signals the breakdown of plant tissues (Lindgren and Miller 2002) and hence elicits broad antiaggregation response from insects that rely on relatively fresh plant tissue for survival and brood production.

Early studies to explore the usefulness of verbenone in the pest management of the mountain pine beetle looked promising (Lindgren et al. 1989). Experiments in which lodgepole pine trees were baited with verbenone (5-8 $\mathrm{mg} /$ day) with or without attractive semiochemical baits showed that the number of mass-attacked trees was reduced and the aggregation process was interrupted in the verbenone-treated plots (Lindgren et al. 1989). These early experiments were conducted at low to moderate mountain pine beetle pressure, which may have promoted the success of the verbenone treatments (Bentz et al. 2005; Progar 2005). Tree baiting experiments using verbenone $(10 \mathrm{mg} /$ day $)$ and only the male-produced aggregation pheromone exobrevicomin showed that verbenone masked the 
attractive effect of the exo-brevicomin baits, which resulted in verbenone-treated trees escaping mass attack (Shore et al. 1992). Later field applications of verbenone against the mountain pine beetle were inconsistent (Borden 1997 and references therein) even when verbenone was released at $20 \mathrm{mg} /$ day (Safranyik et al. 1992), perhaps in part due to the transformation of verbenone under ultraviolet radiation to the inactive by-product chrysanthenone (Kostyk et al. 1993). More recent studies illustrated that high release rates of verbenone ( $>25 \mathrm{mg} /$ day) improve its effectiveness in the protection of lodgepole pine from attack by the mountain pine beetle (Borden et al. 2003), and this formulation was registered in Canada in 2006 (Borden et al. 2007). Trees are further protected if high doses of verbenone are combined with the volatiles released from the bark of non-host angiosperm trees (Borden et al. 2003). Verbenone treatment at the high release rate $(>25 \mathrm{mg} /$ day) successfully protected high-value residential pine trees from mass attack by the mountain pine beetle as part of an IPM programme that included disposal of infested trees (Borden et al. 2007).

Non-host angiosperm tree volatiles: As the results of tree baiting experiments that tested verbenone as a bark beetle antiaggregant were mixed (Borden 1997), research efforts shifted toward investigation of different semiochemicals that could potentially interfere with semiochemical-mediated aggregation of bark beetles. Wilson et al. (1996) showed in electrophysiological studies that mountain pine beetle antennae are responsive to six carbon alcohols that are ubiquitous green leaf volatiles produced by the leaves of angiosperm trees. Traps baited with the antennally active green leaf volatiles in combination with an attractive mountain pine beetle lure significantly reduced trap capture of both male and female beetles compared with that in traps baited with the mountain pine beetle lure alone. Disruption of the aggregation process was highest when the green leaf volatiles were presented as a mixture (Wilson et al. 1996). The two most effective green leaf volatiles, (E)-2-hexen-1-ol and (Z)-3-hexen-1-ol, reduced trap capture in traps baited with the mountain pine beetle lure to a similar degree as verbenone (Wilson et al. 1996). Trees baited with these green leaf volatiles in combination with the attractive mountain pine beetle bait experienced a significantly lower density of attack than trees baited with the attractive bait alone and the level of attack was similar to that of nonbaited trees (Wilson et al. 1996). Green leaf volatiles also disrupt the aggregation response of the western pine beetle, Dendroctonus brevicomis (LeConte) (Coleoptera: Curculionidae: Scolytinae), and the spruce beetle at low (Poland et al. 1998) but not high (Huber and Borden 2003) population densities.

In addition to green leaf volatiles, bark volatiles of non-host angiosperm trees may provide important semiochemical information to host-seeking coniferophagous bark beetles. The volatile blends emitted from six angiosperm trees were collected and pulsed over the antennae of five different species of coniferophagous bark beetles in coupled gas chromatographic-electroantennographic detection analyses (Huber et al. 2000). Of the 25 antennally active compounds recovered, six elicited a response from the antennae of all five bark beetle species tested (Huber et al. 2000), suggesting that in-flight assessment of non-hosts might be an important aspect of host foraging in coniferophagous bark beetles. Incorporation of nonhost bark volatiles into lures emitted from traps reduced the response of the western balsam bark beetle to traps baited with attractive semiochemicals of this species (Huber and Borden 2003). A blend of bark volatiles enhanced the antiaggregation response of the green leaf volatiles to mountain pine beetle (Huber and Borden 2003). A blend of four compounds identified from the bark of trembling aspen, Populus tremuloides (Michaux) (Salicaceae), disrupted mountain pine beetle response to attractant-baited traps by $98 \%$. Of the four bark compounds from trembling aspen that elicit antennal response by the mountain pine beetle, only 1-hexanol was behaviourally active alone and reduced beetle capture in traps baited with attractive semiochemicals (Borden et al. 1998). Conophthorin, a spiroketal that is present in the bark of several nonhost angiosperm trees (Huber et al. 1999), reduced trap capture of Douglas-fir beetle in attractant-baited Lindgren funnel traps (Huber and Borden 2001a). In general, blends of non-host bark volatiles disrupted the aggregation behaviour of bark beetles to a greater extent than individual compounds (Borden et al. 1998; Huber and Borden 2001b, 2003).

Non-host leaf and bark volatiles, with and without the antiaggregation pheromone verbenone, have 
been tested as protectants of lodgepole pine trees from attack by the mountain pine beetle (Huber and Borden 2001b). A smaller proportion of trees baited with blends of non-host bark and green leaf volatiles or verbenone, in addition to an attractive mountain pine beetle bait, were mass attacked compared with trees baited with the attractive bait alone (Huber and Borden 2001b). Disruption of the aggregation response of mountain pine beetle was greatest when trees were baited with a ninecomponent blend of non-host bark and leaf volatiles plus verbenone. This was the case when the plume of the disruptant semiochemicals overlapped or was spatially distinct from that of the attractant semiochemicals (Huber and Borden 2001b). Protection of lodgepole pine from attack by mountain pine beetle was further improved by combining a slightly simpler seven-component blend of non-host bark and leaf volatiles with high doses of verbenone (Borden et al. 2003). Grid baiting at $10-\mathrm{m}$ intervals with the antiaggregation semiochemicals reduced the incidence and density of attack by mountain pine beetle compared with control plots without disruptants (Borden et al. 2003). Disruption of aggregation in response to these repellent semiochemicals would likely work best as part of a "push-pull" management system (defined later) when beetle population densities are low (Borden et al. 2003).

Nonhost bark volatiles have also been tested as repellents to ambrosia beetles (Borden et al. 2001). The antennal receptors of male and female T. lineatum repeatedly responded to six volatile compounds released from angiosperm (non-host) bark. These same compounds were sensed by antennae of two other ambrosia beetle species, G. sulcatus and G. retusus (Borden et al. 2001). Non-host volatiles positioned in multiple-funnel traps interfered with capture of $T$. lineatum in attractive lineatin-baited traps only when blends of two or more non-host compounds were used. Individual non-host volatiles did not interfere with $T$. lineatum orientation to lineatin-baited traps (Borden et al. 2001). Application of a blend of four non-host volatiles (1-hexanol, benzyl alcohol, methyl salicylate, salicylaldehyde) to unattacked logs significantly reduced the number of landings by all three species of ambrosia beetles early in the season. Use of non-host volatiles for $\log$ protection would need to be incorporated with another pest management tactic to achieve season-long control. Pairing repellent and attractive semiochemicals in a push-pull system or the use of other repellent visual or gustatory cues should be tested in this system to enhance operational semiochemical-based control of ambrosia beetles (Borden et al. 2001).

Heterospecific synomones: It is adaptive for insects to detect semiochemicals produced and released by heterospecifics to avoid costly attempts at orientation or aggregation in response to the wrong species or to a resource already occupied by a different species. This would be particularly important for sympatric species that have overlapping pheromone components (Evenden et al. 1999) as is the case for many bark beetles (Pureswaran et al. 2004). Measurement of antennal response of the mountain pine beetle, Douglas-fir beetle, spruce beetle, and and the western balsam bark beetle showed that eight beetle-produced compounds elicited a response from the antennae of all species (Pureswaran et al. 2004), suggesting that beetles are capable of detecting heterospecifics. Combining heterospecific compounds with attractive semiochemical lures can disrupt the aggregation behaviour of the target species. Capture of spruce beetles in Lindgren funnel traps baited with attractive semiochemicals was reduced when traps were additionally baited with the aggregation pheromones of two secondary bark beetles commonly associated with the spruce beetle, Ips tridens Mannerheim and Dryocetes affaber Mannerheim (Coleoptera: Curculionidae: Scolytinae) (Poland and Borden 1998a). Similarly, trap capture of the pine engraver was reduced when traps baited with their aggregation pheromone, ipsdienol, simultaneously released the aggregation pheromone of the heterospecific Ips latidens, ipsenol (Borden et al. 1992). Trapping experiments targeting mountain pine beetle showed that aggregation behaviour could be disrupted by release of 3-methyl-2 cyclohexen-1-one ( $\mathrm{MCH})$, an antiaggregation pheromone of the Douglas-fir and spruce beetles, from traps baited with semiochemicals attractive to the mountain pine beetle (Borden et al. 2004).

Attempts to use heterospecific synomones in pest management of aggressive bark beetles have focussed on two tactics: disruption of host colonisation and competitive displacement (Fig. 3). Disruption of host colonisation was tested in treebaiting experiments targeting the mountain pine 
beetle in which the heterospecific synomone $\mathrm{MCH}$ was used to bait trees in addition to attractive semiochemicals. The $\mathrm{MCH}$ treatment significantly reduced the percentage of lodgepole pine trees that were mass attacked by the mountain pine beetle compared with trees that were baited with the attractive semiochemicals alone (Borden et al. 2004). However, the level of disruption provided by $\mathrm{MCH}$-baited trees was not as great as that provided by verbenone alone, and the combination of $\mathrm{MCH}$ with verbenone and another mountain pine beetle antiaggregation pheromone, 2-phenyl ethanol, did not enhance the activity of verbenone alone (Borden et al. 2004).

Competitive displacement works on the premise that colonisation of the host tree by a secondary bark beetle species can reduce the fitness of the aggressive tree-killing species through competition for resources (Borden 1992). Pheromone baits of the pine engraver, the secondary bark beetle species, induce attack on trees that have been mass attacked by the mountain pine beetle (Rankin and Borden 1991; Safranyik et al. 1996). Co-colonisation by both species of bark beetle reduced the number of mountain pine beetle progeny by $72.5 \%$ compared to that of trees naturally attacked by mountain pine beetle alone (Rankin and Borden 1991). Similarly, offspring production was reduced when logs attacked by the spruce beetle were subsequently baited with pheromones to attract secondary bark beetles. This reduction was not great enough to encourage semiochemicalmediated competitive displacement as a potential pest management tool for spruce beetle (Poland and Borden 1998b). Semiochemical-based competitive displacement has not been operationally adopted but may have potential especially to slow the spread of mountain pine beetle attack by inducing competition for phloem resources with the pine engraver (Rankin and Borden 1991).

\section{Push-pull management strategy}

Exploitation of bark beetle aggregation behaviour and antiaggregation behaviour can be combined to manage bark beetle populations with a "push-pull" tactic (Fig. 3). The push-pull tactic was first tested against the mountain pine beetle using aggregation pheromones plus the attractive host kairomone myrcene to pull beetles toward baited trees and the antiaggregation pheromone verbenone to push beetles away from protected trees (Lindgren and Borden 1993). In an attempt to protect trees in a central zone of each plot, 75 dispensers releasing $5 \mathrm{mg} /$ day of verbenone were positioned evenly throughout a $150 \times 50 \mathrm{~m}$ plot using a $10 \times 10 \mathrm{~m}$ grid pattern in treated plots. In central plot zones treated with verbenone, a lower percentage of trees were mass attacked compared with central zones that were untreated (Lindgren and Borden 1993). Treatment of the zones surrounding the central zones with attractive semiochemicals resulted in a shift in attack distribution so that $>2$ times as many trees were attacked in the pull zones compared with the central push zone. This ratio was only maintained when semiochemicals mediating both antiaggregation and aggregation behaviour were deployed (Lindgren and Borden 1993).

Later operational trials tested some modifications of the push component of the tactic: (1) the combination of non-host volatiles with high doses of verbenone in the absence of the pull component; and (2) the density of antiaggregants in the push component in combination with a surrounding pull component composed of trees baited with aggregation pheromone and myrcene (Borden et al. 2006). Plots treated with high doses of verbenone or nonhost volatiles incurred less attack than areas surrounding the treatment zone but a combination of both types of antiaggregation semiochemicals did not enhance the protection (Borden et al. 2006). The density of antiaggregants in the centrally located 1-ha push component of a 4-ha plot significantly influenced the green: red tree attack ratio, which was lowest in plots receiving the antiaggregants at densities of 44-100 dispensers per ha (Borden et al. 2006). However, protection was not achieved in all replicates that received both the push and pull treatments, and this was attributed to high beetle pressure at the time the experiments were conducted (Borden et al. 2006). These experiments culminated in a recommendation for operational use of the push-pull tactic with high-dose verbenone dispensers that release $100 \mathrm{mg} /$ day positioned at $10-15 \mathrm{~m}$ centres in combination with attractive semiochemicals to concentrate attack and make subsequent removal of infested trees easier. These authors stress that semiochemical-based management of bark beetle populations must be part of an IPM programme that also removes infested trees from the landscape. They provide guidelines of how to use the push-pull tactic when: (1) the density 
of lodgepole pine is $>400$ per ha; (2) the mean diameter at breast height of host trees is $\leqslant 25 \mathrm{~cm}$; and (3) the current level of attack in the stand is $\leqslant 15 \%$ (Borden et al. 2006).

\section{Use of semiochemicals in detection and management of invasive species}

One of the most important uses of semiochemicals in IPM of forest insects is for the early detection of invasive species. Invasive insects are often present initially at low population densities in the new habitat and can be difficult to detect. Semiochemical-baited traps are particularly useful for monitoring insects at low population density (Witzgall et al. 2010) because the olfactory system of insects is so highly tuned to specific chemical cues in the environment. Surveillance programmes for wood boring beetles at ports and in urban environments use Lindgren funnel traps baited with commercially available attractants that are attractive to several species of wood borers (Humble et al. 2003). This approach is useful because the pest manager does not need to know the species identity of the invasive wood borers before trap placement, as kairomone-baited traps attract several wood boring beetles. In many instances, detection of invasive insects dictates immediate management action (Nealis and Erb 1993), and in some cases, semiochemical-based management can be effective at slowing the spread of recently introduced pests (Reardon et al. 1998). Canadian research on the chemical ecology of invasive species ranges from the identification of semiochemicals (Table 1) to the implementation of semiochemicals for monitoring for detection and spread of populations and for control of those species that become established in Canada.

\section{The brown spruce longhorned beetle}

The invasive brown spruce longhorned beetle, Tetropium fuscum (Fabricius) (Coleoptera: Cerambycidae), was first discovered in mature, apparently healthy, red spruce, Picea rubens Sargent (Pinaceae), in Point Pleasant Park, Halifax, Nova Scotia, Canada (Smith and Hurley 2000). In its native Europe, the brown spruce longhorned beetle breeds primarily in stressed or dying Norway spruce, Picea abies (Linnaeus)
Karst. (Juutinen 1955) and is sympatric with T. castaneum (Linnaeus), which also infests stressed or damaged spruce, as well as Pinus and Abies (Sama 2002); Tetropium castaneum is not known to be established in North America. In Nova Scotia, the brown spruce longhorned beetle infests red spruce, white spruce ( $P$. glauca (Moench) Voss), black spruce (P. mariana (Miller) Britton, Sterns, and Poggenburg), and Norway spruce (Smith and Humble 2001; O'Leary et al. 2003) and has been detected in 11 counties (Cunningham 2010). In its new range, the brown spruce longhorned beetle overlaps with the transcontinental, Nearctic T. cinnamopterum Kirby, which infests dying or recently felled spruce and occasionally pines (Furniss and Carolin 1977). The brown spruce longhorned beetle is now an important quarantine pest of spruce in Canada.

The chemical ecology of the brown spruce longhorned beetle has been recently described. Stress-induced compounds in spruce, such as the sesquiterpenes and monoterpenes, are important host kairomones used for host location by beetles (Sweeney et al. 2004, 2006). Attractants for the brown spruce longhorned beetle and the native T. cinnamopterum have been identified as a result of Canadian research (Silk et al. 2007; Sweeney et al. 2010). A blend of spruce monoterpenes (Sweeney et al. 2004) and the male-produced aggregation pheromone ("fuscumol"; $(S)-(E)-6$, 10-dimethyl-5, 9-undecadien-2-ol), can be used to trap the brown spruce longhorned beetle and T. cinnamopterum in Canada and T. castaneum in Europe (Silk et al. 2007; Sweeney et al. 2010). This technology is now in operational use by Canadian Provinces, the United States of America, and the Canadian Food Inspection Agency as a detection tool to measure the annual spread of the brown spruce longhorned beetle. There is some evidence that the spatial spread of this insect is limited (Rhainds et al. 2011), which bodes well for incorporating attractive semiochemicals into a control strategy (Fig. 1). Pheromone-based mating disruption using aerially applied Hercon flakes containing synthetic fuscumol has been tested for suppression of brown spruce longhorned beetle populations to slow its spread. Mating disruption trials by the Canadian Forest Service have proven effective, and registration of this technology is imminent (P.J.S., personal observation); no other technology to detect or control/slow the spread of 
this insect is presently available, so this development is of critical importance.

Canadian research on the chemical ecology of the brown spruce longhorned beetle has also led to fundamental basic discoveries on its reproductive biology and physiology. The "calling" posture of male beetles correlates with the release of pheromone. The presence of other males (chorussing) stimulates calling in the brown spruce longhorned beetle, which suggests that individuals evaluate intrasexual competition and modify pheromone output under competition (Lemay et al. 2010). Stable isotope labelling studies (Mayo et al. 2013) showed that the pheromone is biosynthesised de novo via the mevalonate pathway, mainly in the midgut of male beetles. To further verify this hypothesis, a key mevalonate pathway enzyme, farnesyl diphosphate synthase, was cloned from the brown spruce longhorned beetle. Farnesyl diphosphate synthase generates the sesquiterpene farnesyl diphosphate, which is the immediate precursor of farnesol and is therefore required for the synthesis of fuscumol. Experiments assessing the impact of farnesyl diphosphate synthasedirected RNA interference on fuscumol production should help clarify the role of the mevalonate pathway in fuscumol biosynthesis.

The brown spruce longhorned beetle and T. cinnamopterum also use contact pheromones identified as cuticular hydrocarbons 11methylheptacosane (S11- more active than R11-methylheptacosane) and (9Z)-pentacosene, respectively (Silk et al. 2011b). Both pheromones release conspecific precopulatory and copulatory activity after antennal contact.

\section{The emerald ash borer}

The emerald ash borer, Agrilus planipennis Fairmaire (Coleoptera: Buprestidae), has killed millions of ash (Fraxinus Linnaeus) (Oleaceae) trees in southwestern Ontario, Canada, Michigan, United States of America, and surrounding states (Cappaert et al. 2005). It poses a major economic and environmental threat to urban and forested areas in Canada and the United States of America. Early detection of emerald ash borer infestations has proven very difficult. Visual signs and symptoms, such as D-shaped exit holes on the main stem, epicormic shoots, bark deformities, and thinning crowns, usually appear only on heavily infested trees a year or more after populations have been established (de Groot et al. 2008). Combined research efforts of Canadian and American researchers have led to progress in the development of traps and lures for detection of this pest. Both visual cues, such as the colour purple (Francese et al. 2005, 2007) and cues produced by conspecifics (Lelito et al. 2009), and semiochemical cues have been identified. Emerald ash borer adults are attracted to girdled ash trees (Poland et al. 2004, 2005), green leaf volatiles from ash foliage (Rodriguez-Saona et al. 2006; de Groot et al. 2008), and bark sesquiterpenes emitted by stressed ash (Crook et al. 2008). Crook et al. (2008) identified five antennally active compounds from the bark of green ash, Fraxinus pennsylvanica Marshall (Oleaceae): $\alpha$-cubebene, $\alpha$-copaene, $\quad 7$-epi-sesquithujene, trans- $\beta$-caryophyllene, and $\alpha$-humulene. Many of these components occur in commercially available Manuka oil, except 7-epi-sesquithujene, which, together with the aforementioned compounds, can be found in Phoebe oil (Crook et al. 2008). Purple prism traps baited with Phoebe oil captured more emerald ash borers than unbaited purple traps (Crook et al. 2008). However, with the exception of the rather labour-intensive girdled ash tree method (Poland and McCullough 2006), most of these traps and lures have been tested in areas of high emerald ash borer populations, so their efficacy at detecting low populations in the first year of infestation is unknown.

The chemical ecology of the emerald ash borer has been studied since its detection in North America (Crook and Mastro 2010). Two types of host volatiles are attractive to adults: green leaf volatiles (Poland et al. 2004, 2005, 2006, 2007; Rodriguez-Saona et al. 2006; de Groot et al. 2008; Grant et al. 2010, 2011; Silk et al. 2011a; Crook et al. 2012) and bark sesquiterpenes (Poland and McCullough 2006; Crook et al. 2008; Crook and Mastro 2010; Grant et al. 2010; Cossé et al. 2008; Khrimian et al. 2011). Of the green leaf volatiles, one compound in particular, (3Z)-hexen-1-ol, is highly antennally active and attractive to males in green prism traps (de Groot et al. 2008; Grant et al. 2010; Silk et al. 2011a). Results of these Canadian studies demonstrate that specific host volatiles are important kairomones used by emerald ash borers for host location, and are also useful as trap lures for surveys of early detection. 
Early detection is critical to ash management, and the discovery of a female-produced sex pheromone, the macrocylic lactone, 3Z-dodecen12-olide (3Z-lactone) (Bartelt et al. 2007; Silk et al. 2011a), has provided a more sensitive detection tool for monitoring at low-population levels. It appears to operate at short range as shown by sensory deprivation experiments (Pureswaran and Poland 2009). The activity of this female-produced lactone pheromone is synergised by the host kairomone, (3Z)-hexen-1-ol. Canadian studies have shown that this synergism can be exploited by placement of baited green, sticky, prism traps in the tree canopy where mating occurs (de Groot et al. 2008; Grant et al. 2010) also, addition of (3Z)-lactone to traps significantly increases detection of emerald ash borers at both the trap and plot level, compared with the standard traps baited with (3Z)-hexenol alone (88\% versus $60 \%$, respectively) (Ryall et al. 2012).

The contact sex pheromone of emerald ash borer has been identified as the cuticular hydrocarbon, 9-methylpentacosane (Silk et al. 2009). It appears only on the cuticle of female A. planipennis at sexual maturity (7-10 days old) and stimulates full copulatory activity in males upon antennal contact; 3-methyltricosane may also be involved as an additional component but shows much weaker activity (Lelito et al. 2009).

\section{The European woodwasp}

The detection of the European woodwasp, Sirex noctilio Fabricius (Hymenoptera: Siricidae), in Canada and the United States of America (Ciesla 2003; Hoebeke et al. 2005) highlighted an urgent need to develop a trapping system so that the distribution and density of the wasp can be monitored effectively. Introduction of the European woodwasp in other countries has already resulted in one of the most damaging biological invasions of pine forests in the southern hemisphere and poses a serious threat to pine monocultures (Pinus) in both the United States of America and Canada (de Groot et al. 2006). Although the risk to pine resources in natural northern forests (mixed coniferous and deciduous) is difficult to estimate, the risk to the commercial pines alone is likely considerable.

Several studies have shown that stressed pine trees are primarily attacked by the European woodwasp, apparently attracted by volatiles, which are released from the stem (Simpson 1976). The volatile composition of pine trees and the antennal responses they elicit in the European woodwasp have been studied in some detail by American researchers (Crook et al. 2012). Despite the testing of several promising terpene blends, as well as other treatments, there is still no effective lure that is as attractive as a Lindgren funnel or IPM Tech intercept panel trap placed on trees stressed by trunkinjection with herbicide. A mixture of $\alpha$-pinene (70\%) and $\beta$-pinene $(30 \%)$ is used as a terpene blend for trapping in the United States of America at the present time.

The potential for pheromone-based sexual communication of $S$. noctilio has been examined by American researchers through fractionation of wasp body washes, followed by male copulatory response assays. This approach has led to the identification of three contact sex pheromone components, $(Z)$-7-heptacosene, $(Z)$-7-nonacosene, and (Z)-9-nonacosene (Böröczky et al. 2009). There is currently little evidence that the European woodwasp uses long-range sex pheromone communication, although Cooperband et al. (2012) identified a potential male-produced pheromone candidate, but no field trapping data are available. This compound, (3Z)-decen-1-ol, may, in fact, be a volatile male-produced lek signalling pheromone (Thompson et al. 2013). The natural history of siricid woodwasps is a complex interaction among three organisms: the wasp, a symbiotic wood-rotting fungus, and the host tree. The symbiotic fungus Amylostereum areolatum (Chaillet) Boidin (Amylostereaceae) is essential for growth and development of larvae of the European woodwasp. In addition, the role of esterified sterols in Sirex physiology needs further investigation, and the potential in defining symbiotic associations and pheromone signalling is possibly a fruitful area of research.

\section{The Asian longhorned beetle}

The Asian longhorned beetle, Anoplophora glabripennis (Motschulsky) (Coleoptera: Cerambycidae: Lamiinae), is a serious pest of hardwood trees in Asia, North America, and Europe (Haack et al. 2010). The Asian longhorned beetle attacks living trees, preferring maple Acer Linnaeus and horse chestnut, Aesculus hippocastanum Linnaeus (Sapindaceae) in the United States of America, but other 
hardwood species are also attacked (Haack et al. 2010). The Asian longhorned beetle has enormous destructive potential as it spends much of its life as a grub inside tree trunks and branches causing severe damage and tree death. Few natural enemies have been identified, and only soil or tree injection, and bark spray of insecticides are effective. These control tactics are only viable in urban forestry situations, and widespread eradication efforts are presently being conducted using tree removal, at the cost of billions of dollars. Currently, detection of the Asian longhorned beetle relies on visual inspection for signs of emergence from host trees; thus, efficient monitoring traps are needed to detect populations at ports of entry and to assess population density and dispersal.

Several recent attempts to develop attractants for detection and monitoring of Asian longhorned beetle have produced positive results, but these semiochemicals remain to be tested in Canada. Two male-specific volatiles were found to elicit strong electrophysiological and olfactometric responses from both sexes. These volatiles consist of a 1:1 blend of functionalised dialkyl ethers, 4-(n-heptyloxy) butanal and 4-(n-heptyloxy) butan1-ol (Zhang et al. 2002). Nehme et al. (2010) trapped Asian longhorned beetles with pheromone alone or in combination with plant volatiles. Traps baited with the male-produced pheromone alone caught significantly more females than control traps but only in low numbers. The addition of a mixture of (-)-linalool, (Z3)-hexen-1-ol, linalool oxide, trans-caryophyllene, and trans-pinocarveol to the pheromone significantly increased capture of virgin females. Synergism between pheromone and host kairomones appears important, and further work in this direction would be fruitful. Cuticular hydrocarbon extracts of female Asian longhorned beetles contain five alkenes: (Z9)-tricosene, (Z9)-pentacosene, (Z7)-pentacosene, (Z9)-heptacosene, and (Z7)-heptacosene, which together elicit copulatory behaviour in males (Zhang et al. 2003). There is some evidence that females autooxidise these cuticular olefins to produce antennally active aldehydes (heptanal, nonanal, hexadecanal). Traps baited with blends of these aldehydes combined with linalool oxide and other host kairomones captured more male beetles than unbaited control traps but only low numbers of beetles were captured (Wickham et al. 2012).
In an attempt to use insecticide-treated sentinel trees to monitor the Asian longhorned beetle, five tree genera known to be hosts of the beetle in China were tested for their attractiveness to the beetles. Of the five trees tested, Acer mono Maximowicz was the most attractive and it was significantly more attractive than Acer platanoides Linnaeus, the commonly attacked maple species in the United States of America (Smith et al. 2007). Female Asian longhorned beetles were more attracted to girdled sentinel A. mono trees than intact trees, suggesting a role for plant kairomones in host location in this species (Smith et al. 2007).

Asian longhorned beetles were first detected in 2003 in Toronto, Ontartio, Canada and neighbouring Vaughan. The federal (Canadian Food Inspection Agency) and provincial governments established a "regulated area" to prevent the spread of the insect, taking down 30000 trees and banning the movement of trees, logs, wood, and bark chips from susceptible species throughout the area. As of 2014, the beetle has never been detected anywhere in Canada outside the regulated area. The development of pheromone tools for this insect will aid in the detection of future invasions into Canada.

\section{The banded elm bark beetle}

The banded elm bark beetle, Scolytus schevyrewi Semenov (Coleoptera: Curculionidae: Scolytinae), is an exotic invasive bark beetle native to China and Russia and was first reported in the United States of America in 2003 in elms in Colorado. Although not confirmed, there is concern that the banded elm bark beetle may be a vector of the Dutch elm disease fungus Ophiostoma novo-ulmi Brasier (Ophiostomatoceae). The host range, chemical ecology, and impact of the banded elm bark beetle have been studied in the United States of America (Negroin et al. 2005; LaBonte 2010; Lee et al. 2011), and it is anticipated that this insect will have a significant economic impact on the urban and forested landscapes of North America in the near future.

Lindgren multi funnel-trap catches in Colorado and Nevada, United States of America (Lee et al. 2010) showed that banded elm bark beetles respond to Multilure, a commercial lure for Scolytus multistriatus Marsham (Coleoptera: Curculionidae), the European elm bark beetle. This lure contains mixtures of 2-methy-3-buten-2-ol and mutistriatin 
[(1S,2R,4S,5R)-(-)-2,4-dimethyl-5-ethyl-6,8-dioxabicyclo[3.2.1]octane] (Pearce et al. 1975) and a plant extract. The European elm bark beetle responds much more strongly to this blend than the banded elm bark beetle in trapping assays; both Scolytus Geoffroy species give good electrophysiological responses to 2-methy-3-buten-2-ol, $(+)$ - and (-)- $\alpha$ - pinene and racemic multistratin (Lee et al. 2010). The flight responses of the banded elm bark beetle to plant extracts from Ulmus pumila Linnaeus (Ulmaceae) are described by Lee et al. (2010). Antennal response to (-)- $\alpha$ - pinene is greater in the banded compared to European elm bark beetle; the role of this compound as part of host selection behaviour needs to be explored to potentially help improve the trap bait. The banded elm bark beetle was detected for the first time in Canada near Kelowna, British Columbia in 2010. Fifty-eight beetles were incidentally captured in a set of trapping experiments that targeted the European elm bark beetle (Humble et al. 2010).

\section{Conclusions and synthesis}

Canadian research has advanced semiochemical-based management of forest pests in Canada and around the world. Research has spanned basic questions on signal identification and chemical ecology, to applied management questions emphasising practicality and affordability for the end user. In many instances, semiochemicals have become indispensible tools in forest pest management. The recent registration of a high-dose formulation of verbenone for protection of pine trees from the mountain pine beetle (Borden et al. 2007) and a sprayable mating disruption formulation for the spruce budworm (reviewed in Rhainds et al. 2012) signal receptivity by industrial and government stakeholders of semiochemical-based management tactics. Canadian research has formed the foundation upon which future work can build and hopefully expand the suite of semiochemical-based tools that are operationally available to the forest pest manager.

There is good evidence that climate change has already and will continue to influence the distribution and size of forest insect populations and their hosts. A warming climate is believed to be one of the main drivers in the recent range expansion of the mountain pine beetle (Carroll et al. 2004) that has now reached jack pine on the western edge of the boreal forest (Cullingham et al. 2011). Recent research suggests that the interaction between the mountain pine beetle and its hosts in the expanded range may differ compared with what is known from its historical range (Clark et al. 2010; Cudmore et al. 2010). As this interaction is mediated by semiochemicals, future research should examine how new pine hosts and environmental conditions (Lusebrink et al. 2011, 2013) may influence chemically-mediated interactions and ultimately semiochemical-based management in the expanded range of the beetle.

Climate change and global travel will result in the continued arrival of invasive insect species that may be able to exploit and become established in Canadian forest ecosystems. Canada will need expertise in the taxonomy of insects to identify the invaders as well as chemical ecologists who can identify, synthesise, and apply semiochemical signals to monitor invasive insects that pose a threat to Canada's forest resources and ecosystems. Semiochemical-based monitoring is the only efficient way to monitor introduced species that are typically at low densities at the beginning of the invasion process. Semiochemicals also present an environmentally sound approach to manage invasive species, if they do become established. In the late 1980s, heightened interest in developing ecologically safe methods for managing gypsy moth populations led to the initiation of a mandated Appalachian IPM gypsy moth project in Virginia, with the major goal being to apply mating disruption technology for "slowing the spread" and reducing the impact of gypsy moth populations (Reardon et al. 1998). This was followed in 1993 by the United States Department of Agriculture Forest Service Slow-the-Spread campaign using Hercon-laminated pheromone flakes. These programmes resulted in a successful reduction in the spread of gypsy moth by 35\% from 1988 to 1994 (Sharov et al. 1996) as measured by an elegant modelling of the process (Sharov and Liebhold 1998). This approach to gypsy moth control has not been adopted for established populations in eastern Canada and should be considered as a proven pest management tactic in the future. Mating disruption can be a successful tool to slow the spread of other recently established invasive 
pests such as brown spruce longhorned beetle (P.J.S., personal observation) or to limit population growth of native forest defoliators (Rhainds et al. 2012) that undergo cyclical changes in population density. This semiochemical-based tactic is currently underused in IPM of forest pests in Canada.

Current research on insect chemical ecology in Canada has delved into understanding geographic and genetic variation in chemically mediated interactions that dictate important life-history events. There are several cases in the literature in which geographic and host-associated variation of chemical communication have been identified in insects. In Canada, the sex pheromone signals of the eastern and western hemlock loopers are distinct (Gries et al. 1993a; Li et al. 1993a, 1993b). Populations of the transcontinentally distributed fir coneworm, Dioryctria abietivorella (Grote) (Lepidoptera: Pyralidae) have different pheromone blends (Grant et al. 2009) that dictate the use of different semiochemical-based monitoring tools in eastern and western Canada (Strong et al. 2008). Recent Canadian research has resulted in the publication of the mountain pine beetle genome (Keeling et al. 2013), which will assist researchers in discovering genes that are important for the survival of the beetle in its historical and expanded range. Recent international collaborative efforts involving Canadian scientists (Andersson et al. 2013) have identified protein families important for chemoreception in the mountain pine beetle that could be targets of pest management tactics in the future.

Despite advances in chemical ecology research and applications of semiochemicals to forest pest management, there remain forest insect pests for which the discovery of important semiochemicals remains illusive. Future Canadian research could incorporate strategies such as "reverse chemical ecology" in which important chemical signals may be discovered after odorant binding proteins are characterised using molecular techniques. The odorant receptors can be expressed and tested with a variety of ligands to uncover potential important semiochemicals (Witzgall et al. 2010). New techniques in combination with established, traditional chemical ecology approaches will continue to result in the discovery of semiochemicals of native and invasive forest pests in Canada. With the support of government and industrial stakeholders, semiochemical-based management of forest pests will continue to play a large role in forest IPM in Canada.

\section{Acknowledgements}

The authors thank Drs. Alfaro, Borden, Langor, and Lindgren for their thorough reviews and useful suggestions on former versions of this manuscript. This work was possible due to funding and support of the Evenden laboratory by the University of Alberta, the Natural Sciences and Engineering Research Council of Canada and to the Silk laboratory from the Canadian Forest Service.

\section{References}

Andersson, M.N., Grosse-Wilde, E., Keeling, C.I., Bengtsson, J.M., Yuen, M.M.S., Li, M., et al. 2013. Antennal transcriptome analysis of the chemosensory gene families in the tree killing bark beetles, Ips typographus and Dendroctonus ponderosae (Coleoptera: Curculionidae: Scolytinae). BMC Genomics, 14: 198.

Baker, T.C. and Heath, J.J. 2005. Pheromones function and use in insect control. In Molecular insect science. Volume 6. Edited by L.I. Gilbert, K. Iatro, and S.S. Gill. Elsevier, New York, New York, United States of America. Pp. 407-460.

Barclay, H.J., Safranyik, L., and Linton, D. 1998. Trapping mountain pine beetles, Dendroctonus ponderosae (Coleoptera: Scolytidae), using pheromone-baited traps: effects of trapping distance. Journal of the Entomological Society of British Columbia, 95: 25-31.

Bartell, R.J. 1982. Mechanisms of communication disruption by pheromone in the control of Lepidoptera: a review. Physiological Entomology, 7: 353-364.

Bartelt, R.J., Cosse, A.A., Zilkowski, B.W., and Fraser, I. 2007. Antennally active macrolide from the emerald ash borer Agrilus planipennis emitted predominantly by females. Journal of Chemical Ecology, 33: 1299-1302.

Bauce, É., Carisey, N., Dupont, A., and van Frankenhuyzen, K. 2004. Bacillus thuringiensis subsp. kurstaki aerial spray prescriptions for balsam fir stand protection against spruce budworm (Lepidoptera: Tortricidae). Journal of Economic Entomology, 97: 1624-1634.

Bedard, C., Bennett, R., Gries, G., and Gries, R. 2002. Sex pheromone and diel periodicity of Cydia strobilella (Lepidoptera: Tortricidae) pheromonal communication. The Canadian Entomologist, 134: 847-850.

Bentz, B.J., Kegley, S., Gibson, K., and Their, R. 2005. A test of high-dose verbenone for stand-level protection of lodgepole pine and whitebark pine from mountain pine beetle (Coleoptera: Curculionidae) attacks. Journal of Economic Entomology, 98: 1614-1621. 
Bergh, J.C. and Seabrook, W.D. 1986a. The mating status of spruce budworm males, Choristoneura fumiferana (Clem.) (Lepidoptera: Tortricidae), caught in pheromone-baited traps. Journal of Entomological Science, 21: 254-262.

Bergh, J.C. and Seabrook, W.D. 1986b. A simple technique for indexing the mating status of male spruce budworm, Choristoneura fumiferana (Lepidoptera: Tortricidae). The Canadian Entomologist, 118: 37-41.

Bergh, J.C., Seabrook, W.D., and Eveleigh, E.S. 1988. The mating status of field-collected male spruce budworm, Choristoneura fumiferana (Clem.) (Lepidoptera: Tortricidae), in relation to trap location, sampling method, sampling date, and adult emergence. The Canadian Entomologist, 120: 821-830.

Birgersson, G., Francke, W., Meyer, G., Berisford, C.W., Espelie, K.E., Borden, J.H., et al. 1995. Pheromones in white pine cone beetle, Conophthorus coniperda (Schwarz) (Coleoptera: Scolytidae). Journal of Chemical Ecology, 21: 143-167.

Blatt, S.E., Borden, J.H., Pierce, H.D., Gries, R., and Gries, G. 1998. Alarm pheromone system of the western conifer seed bug, Leptoglossus occidentalis. Journal of Chemical Ecology, 24: 1013-1031.

Borden, J.H. 1989. Semiochemicals and bark beetle populations: exploitation of natural phenomena by pest management strategists. Holarctic Ecology, 12: 501-510.

Borden, J.H. 1990. Use of semiochemicals to manage coniferous tree pests in western Canada. In Behavior-modifying chemicals for insect management. Edited by R. Ridgway, R.M. Silverstein, and M. Inscoe. Marcel Dekker, New York, New York, United States of America. Pp. 281-315.

Borden, J.H. 1992. Two tree baiting tactics for the management of bark beetles with semiochemicals. Journal of Applied Entomology, 114: 201-207.

Borden, J.H. 1993. Strategies and tactics for the use of semiochemicals against forest insect pests in North America. In Pest management: biologically-based technologies. Edited by R.D. Lumsden and J.L. Vaughn. American Chemical Society, Washington, District of Columbia, United States of America. Pp. 265-279.

Borden, J.H. 1997. Disruption of semiochemicalmediated aggregation in bark beetles (Coleoptera: Scolytidae). In Pheromone research: new directions. Edited by R.T. Cardé and A.K. Minks. Chapman and Hall, New York, New York, United States of America. Pp. 421-438.

Borden, J.H., Burleigh, J.S., and Birmingham, A.L. 2006. Evaluation of the push-pull tactic against the mountain pine beetle using verbenone and non-host volatiles in combination with pheromonebaited trees. Forestry Chronicle, 82: 579-590.

Borden, J.H., Chong, L.J., and Fuchs, M.C. 1983a. Application of semiochemicals in post logging manipulation of the mountain pine beetle Dendroctonus ponderosae (Coleoptera: Scolytidae). Journal of Economic Entomology, 76: 1428-1432.
Borden, J.H., Chong, L.J., Gries, R., and Pierce, H.D. Jr. 2001. Potential for nonhost volatiles as repellents in integrated pest management of ambrosia beetles. Integrated Pest Management Reviews, 6: 221-236.

Borden, J.H., Chong, L.J., and Lindgren, B.S. 1980a. Ethanol and alpha-pinene as synergists for the aggregation pheromones of two Gnathotrichus species. Canadian Journal of Forest Research, 10: 290-292.

Borden, J.H., Chong, L.J., McLean, J.A., Slessor, K.N., and Mori, K. 1976. Gnathotrichus sulcatus: synergistic response to enatiomers of the aggregation pheromone sulcatol. Science 192: 894-896.

Borden, J.H., Chong, L.J., Pratt, K.E.G., and Gray, D.R. 1983b. The application of behaviour-modifying chemicals to contain infestations of the mountain pine beetle, Dendroctonus ponderosae. Forestry Chronicle, 59: 235-239.

Borden, J.H., Conn, J.E., Friskie, L.M., Scott, B.E., Chong, L.J., Pierce, H.D. Jr., et al. 1983c. Semiochemicals for the mountain pine beetle Dendroctonus ponderosae (Coleoptera: Scolytidae) in British Columbia Canada: baited tree studies. Canadian Journal of Forest Research, 13: 325-333.

Borden, J.H., Conn, J.E., Pierce, H.D. Jr., Oehlschlager, A.C., and Chong, L.J. 1986. Composition for attracting, and methods of combatting mountain pine beetles. Canadian Patent number 1212044. Canadian Intellectual Property Office, Gatineau Québec, Canada. Available from http://brevets-patents.ic.gc. ca/opic-cipo/cpd/eng/patent/1212044/summary.html? type=number_search [accessed 10 March 2015].

Borden, J.H., Devlin, D.R., and Miller, D.R. 1992. Synomones of two sympatric species deter attack by the pine engraver, Ips pini (Coleoptera: Scolytidae). Canadian Journal of Forest Research, 22: 381-387.

Borden, J.H., Ebata, T.M., Maclauchlan, L.E., Hodgkinson, R.S., Chong, L.J., Lindgren, B.S., et al. 1993. A simplified tree bait for the mountain pine beetle. Canadian Journal of Forest Research, 23: 1108-1113.

Borden, J.H., Gries, G., Chong, L.J., Werner, R.A., Holsten, E.H., Wieser, H., et al. 1996. Regionallyspecific bioactivity of two new pheromones for Dendroctonus rufipennis (Kirby) (Col., Scolytidae). Journal of Applied Entomology, 120: 321-326.

Borden, J.H., Handley, J.R., McLean, J.A., Silverstein, R.M., Chong, L., Slessor, K.N., et al. 1980b. Enantiomer-based specificity in pheromone communication by two sympatric Gnathotrichus species (Coleoptera: Scolytidae). Journal of Chemical Ecology, 6: 445-456.

Borden, J.H., Huber, D.P.W., Earle, T.J., and Chong, L.J. 2003. Protection of lodgepole pine from attack by the mountain pine beetle, Dendroctonus ponderosae (Coleoptera: Scolytidae) using high doses of verbenone in combination with nonhost bark volatiles. Forestry Chronicle, 79: 685-691. 
Borden, J.H. and Lacey, T.E. 1985. Semiochemicalbased manipulation of the mountain pine beetle Dendroctonus ponderosae a component of lodgepole pine Pinus contorta var. latifolia silviculture in the Merritt timber supply area of British Columbia Canada. Zeitschrift Fuer Angewandte Entomologie, 99: 139-145.

Borden, J.H., Lafontaine, J.P., and Pureswaran, D.S. 2008. Synergistic blends of monoterpenes for aggregation pheromones of the mountain pine beetle (Coleoptera: Curculionidae). Journal of Economic Entomology, 101: 1266-1275.

Borden, J.H. and Lindgren, B.S. 1989. The role of semiochemicals in IPM of the mountain pine beetle. In Integrated control of scolytid bark beetles. Edited by T.L. Payne and H. Saarenmaa. Virginia Polytechnic Institute and State Universit, Blacksburg, Virginia, United States of America. Pp. 247-255.

Borden, J.H., Oehlschlager, A.C., Slessor, K.N., Chong, L., and Pierce, H.D. Jr. 1980c. Field tests of isomers of lineatin, the aggregation pheromone of Trypodendron lineatum (Coleoptera: Scolytidae). The Canadian Entomologist, 112: 107-109.

Borden, J.H., Poirier, L.M., and Pureswaran, D.S. 2004. Evaluation of two repellent semiochemicals for disruption of attack by the mountain pine beetle, Dendroctonus ponderosae Hopkins (Coleoptera: Scolytidae). Journal of the Entomological Society of British Columbia, 101: 117-123.

Borden, J.H., Ryker, L.C., Chong, L.J., Pierce, H.D.J., Johnston, B.D., and Oehlschlager, A.C. 1987a. Response of the mountain pine beetle Dendroctonus ponderosae Hopkins (Coleoptera: Scolytidae) to five semiochemicals in British Columbia, Canada lodgepole pine forests. Canadian Journal of Forest Research, 17: 118-128.

Borden, J.H., Sparrow, G.R., and Gervan, N.L. 2007. Operational success of verbenone against the mountain pine beetle in a rural community. Arboriculture and Urban Forestry, 33: 318-324.

Borden, J.H., Stock, A.J., Oehlschlager, A.C., Chong, L.J., Pierce, A.M., and Pierce, H.D. 1987b. Semiochemicals produced by western balsam bark beetle, Dryocoetes confusus Swaine (Coleoptera: Scolytidae). Journal of Chemical Ecology, 13: 823-836.

Borden, J.H., Wilson, I.M., Gries, R., Chong, L.J., Pierce, H.D. Jr., and Gries, G. 1998. Volatiles from the bark of trembling aspen, Populus tremuloides Michx. (Salicaceae) disrupt secondary attraction by the mountain pine beetle, Dendroctonus ponderosae Hopkins (Coleoptera: Scolytidae). Chemoecology, 8: 69-75.

Böröczky, K., Crook, D.J., Jones, T.H., Kenny, J.C., Zylstra, K.E., Mastro, V.C., et al. 2009. Monoalkenes as contact sex pheromone components of the woodwasp Sirex noctilio. Journal of Chemical Ecology, 35: 1202-1211.

Bowers, W.W., Gries, G., Borden, J.H., and Pierce, H.D. 1991. 3 methyl-3-buten-1-ol, an aggregation pheromone of the four-eyed spruce bark beetle Polygraphus rufipennis Kirby (Coleoptera: Scolytidae). Journal of Chemical Ecology, 17: 1989-2002.
Byers, J.A. 2008. Active space of pheromone plume and its relationship to effective attraction radius in applied models. Journal of Chemical Ecology, 34: 1134-1145.

Byrne, K.J., Borden, J.H., Stokkink, E., Swigar, A.A., and Silverstein, R.M. 1974. Sulcatol: population aggregation pheromone in the scolytid beetle, Gnathotrichus sulcatus. Journal of Insect Physiology, 20: 1895-1900.

Camacho, A.D. and Borden, J.H. 1994. Response of the western balsam bark beetle, Dryocoetes confusus Swaine (Coleoptera: Scolytidae), to host trees baited with enantiospecific blends of exo- and endo-brevicomin. The Canadian Entomologist, 126: 43-48.

Camacho, A.D., Borden, J.H., and Pierce, H.D. Jr. 1994. Aggregation pheromones in Dryocoetes affaber (Mann.) (Coleoptera: Scolytidae): stereoisomerism and species specificity. Journal of Chemical Ecology, 20: 111-124.

Camacho, A.D., Pierce, H.D. Jr., and Borden, J.H. 1993. Geometrical and optical isomerism of pheromones in two sympatric Dryocoetes species (Coleoptera: Scolytidae) mediate species specificity and response level. Journal of Chemical Ecology, 19: 2169-2182.

Campbell, S.A. and Borden, J.H. 2005. Bark reflectance spectra of conifers and angiosperms: implications for host selection by coniferophagous bark and timber beetles. The Canadian Entomologist, 137: 719-722.

Campbell, S.A. and Borden, J.H. 2006. Integration of visual and olfactory cues of hosts and non-hosts by three bark beetles (Coleoptera: Scolytidae). Ecological Entomology, 31: 437-449.

Canadian Council of Forest Ministers. 2012. Forest pest knowledge collection and exchange: pest strategy information system. Catalogue number Fo79-7/ 2012E-PDF. Canadian Forest Service, Ottawa, Ontario, Canada. Pp. 1-18. Available from http:// www.ccfm.org/pdf/PestStrat_infosys_2012_en.pdf [accessed 10 March 2015].

Cappaert, D., McCullough, D.G., Poland, T.M., and Siegert, N.W. 2005. Emerald ash borer in North America: a research and regulatory challenge. American Entomologist, 51: 152-165.

Cardé, R.T. 1990. Principles of mating disruption. In Behavior-modifying chemicals for insect management. Edited by R. Ridgway, R.M. Silverstein, and M. Inscoe. Marcel Dekker, New York, New York, United States of America. Pp. 47-71.

Cardé, R.T., Doane, C.C., Baker, T.C., Iwaki, S., and Marumo, S. 1977. Attractancy of optically active pheromone for male gypsy moths. Enviromental Entomology, 6: 768-772.

Carroll, A.L., Taylor, S., Régnière, J., and Safranyik, L. 2004. Effects of climate change on range expansion by the mountain pine beetle in British Columbia. In Mountain pine beetle symposium: challenges and solutions. Edited by T.L. Shore, J.E. Brooks, and J.E. Stone. Natural Resources Canada, Canadian Forest Service, Pacific Forestry Centre, Victoria, British Columbia, Canada. Pp. 223-232. 
Carter, M.E., Smith, M.T., Turgeon, J.J., and Harrison, R.G. 2009. Analysis of genetic diversity in an invasive population of Asian long-horned beetles in Ontario, Canada. The Canadian Entomologist, 141: 582-594.

Chisholm, M.D., Slessor, K.N., Grant, G.G., Underhill, E.W., and Steck, W. 1980. (Z)-5, (E)-7dodecadienal and (Z)-5, (E)-7-dodecadien-1-o1, sex pheromone components of the forest tent caterpillar, Malacosoma disstria. Environmental Entomology, 9: $278-282$.

Ciesla, W.M. 2003. European woodwasp: a potential threat to North America's conifer forest. Journal of Forestry, 101: 18-23.

Clark, E.L., Carroll, A.L., and Huber, D.P.W. 2010. Differences in the constitutive terpene profile of lodgepole pine across a geographical range in British Columbia, and correlation with historical attack by mountain pine beetle. The Canadian Entomologist, 142: 557-573.

Conn, J.E., Borden, J.H., Scott, B.E., Friskie, L.M., Pierce, H.D. Jr., and Oehlschlager, A.C. 1983. Semiochemicals for the mountain pine beetle Dendroctonus ponderosae (Coleoptera: Scolytidae) in British Columbia Canada: field trapping studies. Canadian Journal of Forest Research, 13: 320-324.

Cook, S., Wenz, J., Ragenovich, I., Reardon, R., and Randall, C. 2005. Impact of mating disruption pheromone treatments to control douglas-fir tussock moth, Orgyia pseudotsugata (McDunnough) (Lepidoptera: Lymantriidae) on egg parasitoids. Pan-Pacific Entomologist, 81: 41-46.

Cooperband, M.F., Boeroeczky, K., Hartness, A., Jones, T.H., Zylstra, K.E., Tumlinson, J.H., et al. 2012. Male-produced pheromone in the European woodwasp, Sirex noctilio. Journal of Chemical Ecology, 38: 52-62.

Cory, H.T., Shepherd, R.F., Sanders, C.J., Sower, L.L., Daterman, G.E., and Daves, G.D.J. 1982. Chemistry and field evaluation of the sex pheromone of western spruce budworm, Choristoneura occidentalis, Freeman. Journal of Chemical Ecology, 8: 339-350.

Cossé, A.A., Bartelt, R.J., Zikowski, B.W., and Fraser, I. 2008. Identification and antennal electrophysiology of ash bark volatiles for the emerald ash borer. In Emerald ash borer and asian longhorned beetle research and technology development meeting, Pittsburg, Pennsylvania, 23-24 October 2007. Edited by V. Mastro, D. Lance, R. Reardon, and G. Parra. United States Forest Service, Forest Health Technology Enterprise Team, Morgantown, West Virginia, United States of America. Pp. 81-82.

Crook, D.J., Böröczky, K., Zylstra, K.E., Mastro, V.C., and Tumlinson, J.H. 2012. The chemical ecology of Sirex noctilio. In The sirex woodwasp and its fungal symbiont. Edited by B. Slippers, P. de Groot, and M. Wingfield. Springer, New York, New York, United States of America. Pp. 149-158.
Crook, D.J., Krimian, A., Francese, J., Fraser, I., Poland, T.M., Sawyer, A. J., et al. 2008. Development of a host-based semiochemical lure for trapping emerald ash borer Agrilus planipennis (Coleoptera: Buprestidae). Environmental Entomology, 37: 356-365.

Crook, D.J. and Mastro, V.C. 2010. Chemical ecology of the emerald ash borer. Journal Chemical Ecology, 36: 101-112.

Cudmore, T.J., Björklund, N., Carroll, A.L., and Lindgren, B.S. 2010. Climate change and range expansion of an aggressive bark beetle: evidence of higher beetle reproduction in naïve host tree populations. Journal of Applied Ecology, 47: 1036-1043.

Cullingham, C.I., Cooke, J.E.K., Dang, S., Davis, C.S., Cooke, B.J., and Coltman, D.W. 2011. Mountain pine beetle host-range expansion threatens the boreal forest. Molecular Ecology, 20: 2157-2171.

Cunningham, G. 2010. Update on the brown spruce longhorn beetle (BSLB), Tetropium fuscum (Fabricius), in Nova Scotia, Canada [online]. North American Plant Protection Organization, Phytosanitary alert system official pest report. Available from http://www.pestalert.org/oprDetail.cfm?oprID $=413$ [accessed 23 April 2010].

de Groot, P., Grant, G.G., Poland, T.M., Scharbach, R., Buchan, L., Nott, R.W., et al. 2008. Electrophysiological response and attraction of emerald ash borer to green leaf volatiles (GLVs) emitted by host foliage. Journal of Chemical Ecology, 34: 1170-1179.

de Groot, P., Nystrom, K., and Scarr, T. 2006. Discovery of Sirex noctilio (Hymenoptera: Siricidae) in Ontario, Canada. Great Lakes Entomologist, 39: 49-53.

Dyer, E.D.A. and Safranyik, L. 1977. Assessment of the impact of pheromone baited trees on a spruce beetle population (Coleoptera: Scolytidae). The Canadian Entomologist, 109: 77-80.

Eveleigh, E.S., Lucarotti, C.J., McCarthy, P.C., Morin, B., Royama, T., and Thomas, A.W. 2007. Occurrence and effects of Nosema fumiferanae infections on adult spruce budworm caught above and within the forest canopy. Agricultural and Forest Entomology, 9: 247-258.

Evenden, M.L., Borden, J.H., and Van Sickle, G.A. 1995a. Predictive capabilities of a pheromone-based monitoring system for western hemlock looper (Lepidoptera: Geometridae). Environmental Entomology, 24: 933-943.

Evenden, M.L., Borden, J.H., Van Sickle, G.A., and Gries, G. 1995b. Development of a pheromonebased monitoring system for western hemlock looper (Lepidoptera: Geometridae): effect of pheromone dose, lure age, and trap type. Environmental Entomology, 24: 923-932.

Evenden, M.L., Judd, G.J.R., and Borden, J.H. 1999. A synomone imparting distinct sex pheromone communication channels for Choristoneura rosaceana (Harris) and Pandemis limitata (Robinson) (Lepidoptera: Tortricidae). Chemoecology, 9: 73-80. 
Evenden, M.L., Judd, G.J.R., and Borden, J.H. 2000. Mechanisms of communication disruption of Choristoneura rosaceana, in a pheromone-treated wind tunnel. Journal of Insect Behavior, 13: 499-510.

Francese, J.A., Fraser, I., Lance, D.R., and Mastro, V.C. 2007. Developing survey techniques for emerald ash borer: the role of trap height and design. In Proceedings of the emerald ash borer research and Asian longhorned beetle research and development review meeting. October 29-November 2 2006; Cincinnati, Ohio. Edited by V.C. Mastro, D. Lance, R. Reardon, and G. Parra. FHTET-2007-04. United States Forest Service, Forest Health Technology Enterprise Team, Morgantown, West Virginia, United States of America. Pp. 72-73.

Francese, J.A., Mastro, V.C., Oliver, J.B., Lance, D.R., Youssef, N., and Lavalee, S.G. 2005. Evaluation of colors for trapping Agrilus planipennis (Coleoptera: Buprestidae). Journal of Entomological Science, 40: 93-95.

Fuchs, M.G. and Borden, J.H. 1985. Pre-emergence insecticide applications for control of the mountain pine beetle, Dendroctonus ponderosae (Coleoptera: Scolytidae). Journal of the Entomological Society of British Columbia, 82: 25-28.

Furniss, R.L. and Carolin, V.M. 1977. Western forest insects. Miscellaneous publication 1339, United States Department of Agriculture, Forest Service, Washington, District of Columbia, United States of America.

Grant, G.G. 1978. Field trials on disruption of pheromone communication of tussock moths. Journal of Economic Entomology, 71: 453-457.

Grant, G.G. 1991. Development and use of pheromones for monitoring lepidopteran forest defoliators in North America. Forest Ecology and Management, 39: 153-162.

Grant, G.G., de Groot, P., Langevin, D., Katovich, S.A., Slessor, K.N., and Miller, W.E. 2002. Sex attractants and seasonal flight patterns for three Eucosma (Lepidoptera: Tortricidae) species sympatric in eastern pine seed orchards and plantations. The Canadian Entomologist, 134: 391-401.

Grant, G.G. and Frech, D. 1980. Disruption of pheromone communication of the rusty tussock moth, Orgyia antiqua (Lepidoptera: Lymantriidae), with (Z)-6-heneicosen-11-one. The Canadian Entomologist, 112: 221-222.

Grant, G.G., King, G.G.S., West, R.J., Prevost, Y.H., and Slessor, K.N. 1987a. Identification of the sex pheromone of the spruce coneworm, Dioryctria reniculelloides (Lepidoptera: Pyralidae). Environmental Entomology, 16: 905-909.

Grant, G.G., Lombardo, D.A., Lessor, K.N., Katovich, S.A., and Hall, D.J. 1993. Sex pheromone identification and trapping of Dioryctria resinosella (Lepidoptera: Pyralidae). Environmental Entomology, 22: 154-161.

Grant, G.G., Poland, T.M., Ciaramitaro, T., Lyons, D.B., and Jones, G.C. 2011. Comparison of male and female emerald ash borer (Coleoptera: Buprestidae) responses to phoebe oil and $(Z)$-3-hexenol lures in light green prism traps. Journal of Economic Entomology, 104: 173-179.
Grant, G.G., Ryall, K.L., Lyons, D.B., and Abou-Zaid, M.M. 2010. Differential response of male and female emerald ash borers (Coleoptera: Buprestidae) to (Z)-3-hexenol and Manuka oil. Journal of Applied Entomology, 134: 26-33.

Grant, G.G. and Slessor, K.N. 1983. Sex pheromone of the maple leaf roller Cenopis acerivorana (Lepidoptera: Torticidae). The Canadian Entomologist, 115: 189-194.

Grant, G.G., Slessor, K.N., King, G.G.S., Frech, D., and MacDonald, L. 1987b. Copulation releaser pheromone in body scales of female whitemarked tussock moth, Orgyia leucostigma (Lepidoptera: Lymantriidae): identification and behavioral role. Journal of Chemical Ecology, 13: 345-356.

Grant, G.G., Trudel, R., and Millar, J.G. 2009. Pheromone identification of Dioryctria abietivorella (Lepidoptera: Pyralidae) from an eastern North American population: geographic variation in pheromone response. The Canadian Entomologist, 141: $129-135$.

Gray, D.R. and Borden, J.H. 1989. Semiochemicalbased containment and concentration of mountain pine beetle (Coleoptera: Scolytidae) infestations: validation by sampling of baited and surrounding zones. Journal of Economic Entomology, 82: 1399-1405.

Gray, D.R., Holsten, E., and Pascuzzo, M. 1990. Effects of semiochemical baiting on the attractiveness of felled and unfelled lethal trap trees for spruce beetle Dendroctonus rufipennis Kirby (Coleoptera: Scolytidae) management in areas of high and low beetle populations. The Canadian Entomologist, 122: 373-380.

Gray, T.G., Holsten, E.H., Tracey, A.S., Shepherd, R.F., Slessor, K.N., and Grant, G.G. 1984a. Identification and field testing of pheromone components of Choristoneura orae (Lepidoptera: Tortricidae). Canadian Entomologist, 116: 51-56.

Gray, T.G. and Hulme, M.A. 1995. Mating disruption of Douglas-fir tussock moth one and two years after the application of pheromone. Journal of the Entomological Society of British Columbia, 92: 101-105.

Gray, T.G., Manville, J.F., Grant, G.G., and Slessor, K.N.S. 1984b. European pine shoot moth, Rhyacionia buoliana (Lepidoptera: Tortricidae): identification of additional pheromone components resulting in an improved lure. The Canadian Entomologist, 116: 1525-1532.

Greenbank, D.O., Schaefer, G.W., and Rainey, R.C. 1980. Spruce budworm (Lepidoptera: Tortricidae) moth flight and dispersal: new understanding from canopy observations, radar, and aircraft. Memoirs of the Entomological Society of Canada, 110: $1-49$.

Greenwood, M.E. and Borden, J.H. 2000. Co-baiting for spruce beetles, Dendroctonus rufipennis (Kirby), and western balsam bark beetles, Drycoetes confusus Swaine (Coleoptera: Scolytidae). Canadian Journal of Forest Research, 30: 50-58. 
Gries, G., Borden, J.H., Gries, R., Lafontaine, J.P., Dixon, E.A., Wieser, H., et al. 1992. 4-Methylene6,6-dimethylbicyclo [3.1.1] hept-2-ene (Verbenene): new aggregation pheromone of the scolytid beetle Dendroctonus rufipennis. Naturwissenschaften, 79: 367-368.

Gries, G., Bowers, W.W., Borden, J.H., Underhill, E.W., West, R.J., Slessor, K.N., et al. 1993a. Sex pheromone of the western hemlock looper, Lambdina fiscellaria lugubrosa (Hulst) (Lepidoptera: Geometridae). Journal of Chemical Ecology, 19: 1009-1019.

Gries, G., Grant, G.G., Gray, T.G., Hulme, M., Tracey, A.S., Gries, R., et al. 1997. (Z) 6, (E) 8-heneicosadien-11-one: synergistic sex pheromone component of Douglas-fir tussock moth, Orgyia pseudotsugata (McDunnough) (Lepidoptera: Lymantriidae). Journal of Chemical Ecology, 23: 19-34.

Gries, G., Gries, R., Khaskin, G., Slessor, K.N., Grant, G.G., Liška, J., et al. 1996. Specificity of nun and gypsy moth sexual communication through multiple-component pheromone blends. Naturwissenschaften, 83: 382-385.

Gries, G., Humble, L., Underhill, E.W., and Gries, R. $1993 b$. (6Z,9Z-3R,4S)-epoxy-heptadecadiene: major sex pheromone component of the larch looper, Semiothisa sexmaculata (Packard) (Lepidoptera: Geometridae). Journal of Chemical Ecology, 19: 843-850.

Gries, G., Khaskin, G., Wimalaratne, P.D.C., Slessor, K.N., King, G.G.S., Gries, R., et al. 1994a. (E)-11,13-tetradecadienal: major sex pheromone component of the eastern blackheaded budworm, Acleris variana (Fern.) (Lepidoptera: Tortricidae). Journal of Chemical Ecology, 20: 1-8.

Gries, G., Li, J., Shepherd, R.F., Khaskin, G., Slessor, K.N., Gries, R., et al. 1993c. 3,13-dimethylheptadecane: major sex pheromone component of the western false hemlock looper, Nepytia freemani Munroe (Lepidoptera: Geometridae). Journal of Chemical Ecology, 19: 1501-1510.

Gries, G., Pierce, H.D. Jr., Lindgren, B.S., and Borden, J.H. 1988. New techniques for capturing and analyzing semiochemicals for scolytid beetles. Journal of Economic Entomology, 81: 1715-1720.

Gries, R., Burden, K., Gries, G., Miroshnychenko, A., Khaskin, G., and Bennett, R.G. 2005a. (S,S)-2,12-, 2,13-, and (S,S)-2,14-diacetoxyheptadecanes: sex pheromone components of red cedar cone midge, Mayetiola thujae. Journal of Chemical Ecology, 31: 2933-2946.

Gries, R., Gotoh, T., Gries, G., Hahn, R., Khaskin, G., and Schaefer, P.W. 2005b. (7R,8S)-cis-7,8-epoxy-2methyloctadec-17-ene: a novel trace component from the sex pheromone gland of gypsy moth, Lymantria dispar. Journal of Chemical Ecology, 31: 49-62.

Gries, R., Khaskin, G., Gries, G., Bennett, R.G., Skip King, G.G., Morewood, P., et al. 2002. (Z,Z)-4,7tridecadien- $(S)-2-y l$ acetate: sex pheromone of the Douglas-fir cone gall midge, Contarinia oregonensis. Journal of Chemical Ecology, 28: 2283-2297.
Gries, R., Lemmon, C.R., Slessor, K.N., Maier, C.T., Gries, G., and Li, J. 1994b. Sex pheromone components of the spring hemlock looper, Lambdina athasaria (Walker) (Lepidoptera: Geometridae). Journal of Chemical Ecology, 20: 2501-2511.

Gries, R., Schaefer, P.W., Gries, G., Foltz, J.L., Khaskin, G., and Khaskin, E. 2003. Enantiomers of (Z,Z)-6,9-heneicosadien-11-ol: sex pheromone components of Orgyia detrita. Journal of Chemical Ecology, 29: 2201-2212.

Gut, L.J., Stelinski, L.L., Thomson, D.R., and Miller, J.R. 2004. Behavior-modifying chemicals: prospects and constraints in IPM. In Integrated pest management potential, constraints, and challenges. Edited by O. Koul, G.S. Dhaliwal, and G. Cuperus. CABI Press, New York, New York, United States of America. Pp. 73-121.

Haack, R.A., Hérard, F., Sun, J., and Turgeon, J. 2010. Managing invasive populations of Asian longhorned beetle and citrus longhorned beetle: a worldwide perspective. Annual Review of Entomology, 55: 521-546.

Hagaman, T.E. and Cardé, R.T. 1984. Effect of pheromone concentration on organization of preflight behaviors of the male gypsy moth, Lymantria dispar (L.). Journal of Chemical Ecology, 10: $17-23$.

Haynes, K.F. and Yeargan, K.V. 1999. Exploitation of intraspecific communication systems: illicit signalers and receivers. Annals Entomological Society of America, 92: 960-970.

Heeley, T., Alfaro, R.I., Humble, L., and Strong, W. 2003. Distribution and life cycle of Rhyacionia buoliana (Lepidoptera: Tortricidae) in the interior of British Columbia. Journal of the Entomological Society of British Columbia, 100: 19-25.

Hoebeke, E.R., Haugen, D.A., and Haack, R.A. 2005. Sirex noctilio: discovery of a Palearctic siricid woodwasp in New York. Newsletter of the Michigan Entomological Society, 50: 24-25.

Houseweart, M.W., Sanders, C.J., and Jennings, D.T. 1981. Variables associated with pheromone traps for monitoring spruce budworm populations (Lepidoptera: Tortricidae). The Canadian Entomologist, 113: 527-537.

Huber, D.P.W. and Borden, J.H. 2001a. Protection of lodgepole pines from mass attack by mountain pine beetle, Dendroctonus ponderosae, with nonhost angiosperm volatiles and verbenone. Entomologia Experimentalis et Applicata, 99: 131-141.

Huber, D.P.W. and Borden, J.H. 2001b. Angiosperm bark volatiles disrupt response of Douglas-fir beetle, Dendroctonus pseudotsugae, to attractantbaited traps. Journal of Chemical Ecology, 27: 217-233.

Huber, D.P.W. and Borden, J.H. 2003. Comparative behavioural responses of Dryocoetes confuses Swaine, Dendroctonus rufipennis (Kirby), and Dendroctonus ponderosae Hopkins (Coleoptera: Scolytidae) to angiosperm tree bark volatiles. Environmental Entomology, 32: 742-751. 
Huber, D.P.W., Gries, R., Borden, J.H., and Pierce, H.D. Jr. 1999. Two pheromones of coniferophagous bark beetles found in the bark of non-host angiosperms. Journal of Chemical Ecology, 25: 805-816.

Huber, D.P.W., Gries, R., Borden, J.H., and Pierce, H.D. Jr. 2000. A survey of antennal responses by five species of coniferophagus bark beetles (Coleoptera: Scolytidae) to bark volatiles of six species of angiosperm trees. Chemoecology, 10: 103-113.

Hulme, M. and Gray, T. 1994. Mating disruption of Douglas-fir tussock moth (Lepidoptera: Lymantriidae) using a sprayable bead formulation of Z-6-heneicosen-11-one. Environmental Entomology, 23: 1097-1100.

Hulme, M. and Gray, T. 1996. Effect of pheromone dosage on the mating disruption of Douglas-fir tussock moth. Journal of the Entomological Society of British Columbia, 93: 99-103.

Humble, L.M., Allen, E.A., Hurley, E., Sun, J.H., Gao, C.Q., and Gill, B.D. 2003. Surveillence for invasive wood borers: national and international perspectives [online]. 0724-B3 XII. World Forestry Congress, Ville de Québec, Québec, Canada. Available from http://www.fao.org/docrep/article/wfc/xii/0724-b3. htm [accessed 3 March 2015].

Humble, L.M., Smith, J.E., Zilahi-Balogh, G.M.G., Kimoto, T., and Noseworthy, M.K. 2010. First records of the banded elm bark beetle, Scolytus schevyrewi Semenov (Coleoptera: Curculionidae: Scolytinae), in British Columbia. Journal of the Entomological Society of British Columbia, 107: 21-24.

Humble, L.M. and Stewart, A.J. 1994. Forest pest leaflet 75: gypsy moth. Catalogue number Fo29-6/ 75-1994E. Natural Resources Canada, Canadian Forest Service, Victoria, British Columbia, Canada. Available from http://cfs.nrcan.gc.ca/pubwarehouse/ pdfs/3456.pdf [accessed 10 March 2015].

Hunt, D.W.A. and Borden, J.H. 1990. Conversion of verbenols to verbenone by yeasts isolated from Dendroctonus ponderosae (Coleoptera: Scolytidae). Journal of Chemical Ecology, 16: 1385-1397.

Hunt, D.W.A., Gries, G., Lindgren, B.S., and Borden, J.H. 1989. The role of autoxidation of alpha-pinene in the production of pheromones of Dendroctonus ponderosae (Coleoptera: Scolytidae). Canadian Journal of Forest Research 19: 1275-1282.

Jeans-Williams, N. and Borden, J.H. 2006. Evaluation of two pheromone baits for containment and concentration of attack by the western balsam bark beetle, Dryocoetes confusus (Coleoptera: Curculionidae). Western Journal of Applied Forestry, 21: 27-32.

Jones, B.C. and Evenden, M.L. 2008. Ecological applications for pheromone trapping of Malacosoma disstria and Choristoneura conflictana. The Canadian Entomologist, 140: 573-581.

Jones, B.C., Roland, J., and Evenden, M.L. 2009. Development of a combined sex pheromone-based monitoring system for Malacosoma disstria (Lepidoptera: Lasiocampidae) and Choristoneura conflictana (Lepidoptera: Tortricidae). Environmental Entomology, 38: 459-471.
Juutinen, P. 1955. Zur Biologie und forstlichen Bedeutung der Fichtenböcke (Tetropium Kirby) in Finland. Acta Entomological Fennica, 11: 1-112.

Keeling, C.I., Yuen, M.M.S., Liao, N.Y., Docking, T.R., Chan, S.K., Taylor, G.A., et al. 2013. Draft genome of the mountain pine beetle, Dendroctonus ponderosae Hopkins, a major forest pest. Genome Biology, 14: R27.

Khrimian, A., Cossé, A.A., and Crook, D.J. 2011. Absolute configuration of 7-epi-Sesquithujene. Journal of Natural Products, 74: 1414-1420.

King, G.G.S., Slessor, K.N., Gries, G., and Gries, R. 1995. Optical isomers of 1,13-dimethylheptadecane: sex pheromone components of the western false hemlock looper, Nepytia freemani (Lepidoptera: Geometridae). Journal of Chemical Ecology, 21: 2027-2045.

Kostyk, B.C., Gries, G., and Borden, J.H. 1993. Photoisomerization of antiaggregation pheromone verbenone: biological and practical implications with respect to the mountain pine beetle, Dendroctonus ponderosae Hopkins (Coleoptera: Scolytidae). Journal of Chemical Ecology, 19: 1749-1759.

Kühnholz, S. 2004. Chemical ecology and mechanisms of reproductive isolation in ambrosia beetles. Ph.D. thesis. Simon Fraser University, Burnaby, British Columbia, Canada. Available from: http://summit. sfu.ca/item/8474 [accessed 10 March 2015].

LaBonte, J.R. 2010. The banded elm bark beetle, Scolytus schevyrewi Semenov (Coleoptera: Curculionidae: Scolytinae) in North America: a taxonomic review and modifications to the Wood (1982) key to the species of Scolytus Geoffroy in central North America. ZooKeys, 56: 207-218.

Laidlaw, W.G., Fabris, S., Wieser, H., Prenzel, B.G., and Reid, M.L. 2003. Comparison of the efficacy of pheromone-baited traps, pheromone-baited trees, and felled trees for the control of Dendroctonus pseudotsugae (Coleoptera: Scolytidae). Environmental Entomology, 32: 477-483.

Lawson, D.S., Reissig, W.H., Agnello, A.M., Nyrop, J.P., and Roelofs, W.L. 1996. Interference with the matefinding communication system of the obliquebanded leafroller (Lepidoptera: Tortricidae) using synthetic sex pheromones. Environmental Entomology, 25: 895-905.

Lee, J.C., Hamud, S.M., Negron, J.F., Witcosky, J.J., and Seybold, S.J. 2010. Semiochemical-mediated flight strategies of two invasive elm bark beetles: a potential factor in competitive displacement. Environmental Entomology, 39: 642-652.

Lee, J.C., Negroin, J.F., McElwey, S.J., Williams, L., Witcosky, J.J., Popp, J.B., et al. 2011. Biology of the invasive banded elm bark beetle (Coleoptera: Scolytidae) in the western United States. Annals of the Entomological Society of America, 104: 705-717.

Lelito, J.P., Boeroeczky, K., Jones, T.H., Fraser, I., Mastro, V.C., Tumlinson, J.H., et al. 2009. Behavioral evidence for a contact sex pheromone component of the emerald ash borer, Agrilus planipennis Fairmaire. Journal of Chemical Ecology, 35: $104-110$. 
Lemay, M.A., Silk, P.J., and Sweeney, J. 2010. Calling behavior of Tetropium fuscum (Coleoptera: Cerambycidae: Spondylidinae). The Canadian Entomologist, 142: 256-260.

Li, J., Bikic, J., Slessor, K.N., Gries, G., and Gries, R. 1993a. Chirality of synergistic sex pheromone components of the western hemlock looper Lambdina fiscellaria lugubrosa (Hulst) (Lepidoptera: Geometridae). Journal of Chemical Ecology, 19: 2547-2561.

Li, J.X., King, G.G.S., Bowers, W.W., West, R.J., Gries, R., Gries, G., et al. 1993b. Chirality of 5,11dimethylheptadecane, the major sex pheromone component of the hemlock looper, Lambdina fiscellaria (Lepidoptera: Geometridae). Journal of Chemical Ecology, 19: 1057-1062.

Liebhold, A.M., Luzader, E., Reardon, R., Roberts, A., Ravlin, F.W., Sharon, A., et al. 1998. Forecasting gypsy moth (Lepidoptera: Lymantriidae) defoliation with a geographical information system. Journal of Economic Entomology, 91: 464-472.

Lindgren, B.S. 1983. A multiple funnel trap for scolytid beetles (Coleoptera). The Canadian Entomologist, 115: 299-302.

Lindgren, B.S. 1990. Ambrosia beetles. Journal of Forestry, 88: 8-11.

Lindgren, B.S. and Borden, J.H. 1983. Survey and mass trapping of ambrosia beetles (Coleoptera: Scolytidae) in timber processing areas on Vancouver Island Canada. Canadian Journal of Forest Research, 13: $481-493$.

Lindgren, B.S. and Borden, J.H. 1993. Displacement and aggregation of mountain pine beetles, Dendroctonus ponderosae (Coleoptera: Scolytidae), in response to their antiaggregation and aggregation pheromones. Canadian Journal of Forest Research 23: 286-290.

Lindgren, B.S., Borden, J.H., Cushon, G.H., Chong, L.J., and Higgins, C.J. 1989. Reduction of mountain pine beetle (Coleoptera: Scolytidae) attacks by verbenone in lodgepole pine stands in British Columbia Canada. Canadian Journal of Forest Research, 19: 65-68.

Lindgren, B.S. and Fraser, R.G. 1994. Control of ambrosia beetle damage by mass trapping at a dryland log sorting area in British Columbia. Forestry Chronicle, 70: 159-163.

Lindgren, B.S. and Miller, D.R. 2002. Effect of verbenone on five species of bark beetles (Coleoptera: Scolytidae) in lodgepole pine forests. Environmental Entomology, 31: 759-765.

Lindgren, B.S., Mori, K., Pierce, H.D. Jr., and Gries, G. 1992. Dendroctonus pseudotsugae Hopkins (Coleoptera: Scolytidae): production of and response to enantiomers of 1-methylcyclohex-2-en-1-ol. Journal of Chemical Ecology, 18: 1201-1208.

Lusebrink, I., Erbilgin, N., and Evenden, M.L. 2013. The lodgepole $\times$ jack pine hybrid zone in Alberta, Canada: a stepping stone for the mountain pine beetle on its journey east across the boreal forest? Journal of Chemical Ecology, 39: 1209-1220.
Lusebrink, I., Evenden, M.L., Blanchet, F.G., Cooke, J.E.K., and Erbilgin, N. 2011. Effect of water stress and fungal inoculation on monoterpene emission from an historical and a new pine host of the mountain pine beetle. Journal of Chemical Ecology 37: 1013-1026.

MacConnell, J.G., Stokkink, E., Silverstein, R.M., and Borden, J.H. 1977. Isolation and tentative identification of lineatin, a pheromone from the frass of Trypodendron lineatum (Coleoptera: Scolytidae). Journal of Chemical Ecology, 5: 549-561.

Macias-Samano, J., Gries, R., Gries, G., Borden, J.H., and Pierce, H.D. Jr. 1997. Aggregation pheromone of Pityokteines elegans. Journal of Chemical Ecology, 23: 1333-1347.

Maclauchlan, L.E., Borden, J.H., D’Auria, J.M., and Wheeler, L.A. 1988. Distribution of arsenic in MSMA-treated lodgepole pines infested by the mountain pine beetle, Dendroctonus ponderosae Hopkins (Coleoptera: Scolytidae), and its relationship to beetle mortality. Journal of Economic Entomology, 81: 274-280.

Maclauchlan, L.E. and Brooks, J.E. 1998. Strategies and tactics for managing the mountain pine beetle, Dendroctonus ponderosae. B.C. Forest Service, Kamloops Region Forest Health, Kamloops, British Columbia, Canada.

Maclauchlan, L.E., Brooks, J.E., Borden, J.H., and Harder, L. 2003. Impact of the western balsam bark beetle, Dryocoetes confusus Swaine (Coleoptera: Scolytidae), at the Sicamous Creek research site, and the potential for semiochemical based management in alternative silviculture systems. Journal of the Entomological Society of British Columbia, 100: 27-41.

Mayo, P., Silk, P.J., Cusson, M., and Béliveau, C. 2013. Steps in the biosynthesis of Fuscumol in the longhorn beetles Tetropium fuscum and Tetropium cinnamopterum (Coleoptera: Cerambycidae: Spondylidinae). Journal of Chemical Ecology, 39: 377-389.

McLean, J.A., Bakke, A., and Niemeyer, H. 1987. An evaluation of three traps and two lures for the ambrosia beetle Trypodendron lineatum Oliv. (Coleoptera: Scolytidae) in Canada, Norway, and West Germany. The Canadian Entomologist, 119: 273-280.

McLean, J.A. and Borden, J.H. 1977. Attack by Gnathotrichus sulcatus (Coleoptera: Scolytidae) on stumps and felled trees baited with sulcatol and ethanol. The Canadian Entomologist, 109: 675-686.

McLean, J.A. and Borden, J.H. 1979. An operational pheromone based suppression program for an ambrosia beetle Gnathotrichus sulcatus in a commercial sawmill. Journal of Economic Entomology, 72: $165-172$.

Millar, J.G., Rudolph, C., Stein, J.D., Moreira, J.A., Grant, G.G., McElfresh, J.S., et al. 2005. (3Z,6Z,9Z,12Z,15Z)-pentacosapentaene, a key pheromone component of the fir coneworm moth, Dioryctria abietivorella. Journal of Chemical Ecology, 31: 1229-1234. 
Miller, D.R., Borden, J.H., and Gries, G. 1990. E-myrcenol: a new pheromone for the pine engraver, Ips pini (Say) (Coleoptera: Scolytidae). The Canadian Entomologist, 122: 401-406.

Miller, D.R., Borden, J.H., King, G.G.S., and Slessor, K.N. 1991. Ipsenol: an aggregation pheromone for Ips latidens (LeConte) (Coleoptera: Scolytidae). Journal of Chemical Ecology, 17: 1517-1527.

Miller, D.R., Borden, J.H., and Lindgren, B.S. 2005. Dose-dependent pheromone responses of mountain pine beetle in stands of lodgepole pine. Environmental Entomology, 34: 1019-1027.

Miller, D.R., Lindgren, B.S., and Borden, J.H. 1995. Verbenone: dose-dependent interruption of pheromone-based attraction of three sympatric species of pine bark beetles (Coleoptera: Scolytidae). Environmental Entomology, 24: 692-696.

Miller, D.R., Pierce, H.D. Jr., de Groot, P., JeansWilliams, N., Bennett, R., and Borden, J.H. 2000. Sex pheromone of Conophthorus ponderosae (Coleoptera: Scolytidae) in a coastal stand of western white pine (Pinaceae). The Canadian Entomologist, 132: 243-245.

Moeck, H.A. 1970. Ethanol as the primary attractant for the ambrosia beetle, Trypodendron lineatum (Coleoptera: Scolytidae). The Canadian Entomologist, 102: 985-995.

Morrissey, C.A., Albert, C.A., Dods, P.L., Cullen, W.R., Lai, V.W.M., and Elliott, J.E. 2007. Arsenic accumulation in bark beetles and forest birds occupying mountain pine beetle infested stands treated with monosodium methanearsonate. Environmental Science and Technology, 41: 1494-1500.

Morrissey, C.A., Dods, P.L., and Elliott, J.E. 2008. Pesticide treatments affect mountain pine beetle abundance and woodpecker foraging behavior. Ecological Application, 18: 172-184.

Nealis, V. 2009. Still invasive after all these years: keeping gypsy moth out of British Columbia. Forestry Chronicle, 85: 593-603.

Nealis, V. and Erb, S. 1993. A sourcebook for management of the gypsy moth. Catalogue number Fo42-193/1993E. Forestry Canada, Great Lakes Forestry Centre, Sault Ste. Marie, Ontario, Canada.

Negroin, J.F., Witcosky, J.J., Cain, R.J., LaBonte, J.R., Duerr, D.A., McElwey, S.J., et al. 2005. The banded elm bark beetle: a new threat to elms in North America. American Entomologist, 51: 84-94.

Nehme, M., Keena, M., Zhang, A., Baker, T., Xu, Z., and Hoover, K. 2010. Field testing of Anoplophora glabripennis male-produced pheromone and plant volatiles. Environmental Entomology, 39: 169-176.

Nordlund, D.A. and Lewis, W.J. 1976. Terminology of chemical releasing stimuli in intraspecific and interspecific interactions. Journal of Chemical Ecology, 2: 211-220.
O'Leary, K., Hurley, J.E., MacKay, W., and Sweeney, J. 2003. Radial growth rate and susceptibility of Picea rubens Sarg. to Tetropium fuscum (Fabr.). In Proceedings: ecology, survey and management of forest insects. Edited by M.L. McMannus and A.M. Liebhold. United States Department of Agriculture, Forest Service, Newtown Square, Pennsylvania, United States of America. Pp. 107-114.

Palaniswamy, P. and Seabrook, W.D. 1978. Behavioral responses of the female eastern spruce budworm Choristoneura fumiferana (Lepidoptera: Tortricidae) to the sex pheromone of her own species. Journal of Chemical Ecology, 4: 649-655.

Palanisawmy, P., Wiesner, C.J., Tan, S.H., Silk, P.J., Ross, R.J., Seabrook, W.D., et al. 1982. Mating suppression of caged spruce budworm (Lepidoptera: Tortricidae) moths in different pheromone atmospheres and high population densities. Journal of Economic Entomology, 75: 989-993.

Pearce, G.T., Gore, W.E., Silverstein, R.M., Peacock, J.W., Cuthbert, R.A., Lanier, G.N., et al. 1975. Chemical attractants for the smaller European bark beetle, Scolytus multistriatus (Coleoptera: Scolytidae). Journal of Chemical Ecology, 1: 115-124.

Pierce, H.D. Jr., Ramaswamy, S., Oehlschlager, A.C., de Groot, P., and Borden, J.H. 1995. Pheromones in red pine cone beetle, Conophthorus resinosae Hopkins, and its synonym, C. banksianae McPherson (Coleoptera: Scolytidae). Journal of Chemical Ecology, 21: 169-185.

Pitman, G.B. 1973. Further observations on Douglure in a Dendroctonus pseudotsugae management system. Environmental Entomology, 2: 109-112.

Poland, T.M. and Borden, J.H. 1997. Attraction of a bark beetle predator, Thanasimus undatulus (Coleoptera: Cleridae), to pheromones of the spruce beetle and two secondary bark beetles (Coleoptera: Scolytidae). Journal of the Entomological Society of British Columbia, 94: 35-41.

Poland, T.M. and Borden, J.H. 1998a. Disruption of secondary attraction of the spruce beetle, Dendroctonus rufipennis, by pheromones of two sympatric species. Journal of Chemical Ecology, 24: 151-166.

Poland, T.M. and Borden, J.H. 1998b. Competitive exclusion of Dendroctonus rufipennis induced by pheromones of Ips tridens and Dryocoetes affaber (Coleoptera: Scolytidae). Journal of Economic Entomology, 91: 1142-1149.

Poland, T.M., Borden, J.H., Stock, A.J., and Chong, L.J. 1998. Green leaf volatiles disrupt responses by the spruce beetle, Dendroctonus rufipennis, and western pine beetle, Dendroctonus brevicomis (Coleoptera: Scolytidae) to attractant-baited traps. Journal of Entomological Society of British Columbia, 95: 17-24. 
Poland, T.M., de Groot, P., Grant, G.G., Macdonald, L., and McCullough, D.G. 2004. Developing attractants and trapping techniques for the emerald ash borer. In Emerald ash borer research and technology development meeting, Port Huron, Michigan, 30 September to 1 October 2003. Edited by V. Mastro and R. Reardon. United States Forest Service, Forest Health Technology Enterprise Team, Morgantown, West Virginia, United States of America. Pp. 15-16.

Poland, T.M. and McCullough, D.G. 2006. Emerald ash borer: invasion of the urban forest and the threat to North America's ash resource. Journal of Forestry, 104: 118-124.

Poland, T.M., McCullough, D.G., de Groot, P., Grant, G.G., MacDonald, L., and Cappaert, D.L. 2005. Progress toward developing trapping techniques for the emerald ash borer. In Emerald ash borer research and technology development meeting, Romulus, Michigan, 5-6 October 2004. Edited by V. Mastro and R. Reardon. United States Forest Service, Forest Health Technology Enterprise Team, Morgantown, West Virginia, United States of America. Pp. 53-54.

Poland, T.M., Pureswaren, D.S., Grant, G.G., and de Groot, P. 2007. Field attraction of emerald ash borer to antennally and behaviorally active ash volatiles. In Emerald ash borer research and technology development meeting, Cincinnati, Ohio, 29 October-2 November 2006. Edited by V. Mastro, D. Lance, R. Reardon, and G. Parra. United States Forest Service, Forest Health Technology Enterprise Team, Morgantown, West Virginia, United States of America. Pp. 80-81.

Poland, T.M., Rodriguez-Saona, C., Grant, G.G., Buchan, L., de Groot, P., and Miller, J. 2006. Trapping and detection of emerald ash borer: identification of stress-induced volatiles and tests of attraction in the lab and field. In Emerald ash borer research technology development meeting, Pittsburgh, Pennsylvania, 26-27 September 2005. Edited by V. Mastro, R. Reardon, and G. Parra. United States Forest Service, Forest Health Technology Enterprise Team, Morgantown, West Virginia, United States of America. Pp. 64-65.

Progar, R.A. 2005. Five-year operational trial of verbenone to deter mountain pine beetle (Coleoptera: Scolytidae) attack of lodgepole pine (Pinus controta). Environmental Entomology, 34: 1402-1407.

Pureswaran, D.S. and Borden, J.H. 2005. Primary attraction and kairomonal host discrimination in three species of Dendroctonus (Coleoptera: Scolytidae). Agricultural and Forest Entomology, 7: 219-230.

Pureswaran, D.S., Gries, R., and Borden, J.H. 2004. Antennal responses of four species of tree-killing bark beetles (Coleoptera: Scolytidae) to volatiles collected from beetles, and their host and nonhost conifers. Chemoecology, 14: 59-66.

Pureswaran, D.S., Gries, R., Borden, J.H., and Pierce, H.D. Jr. 2001. Dynamics of pheromone production and communication in the mountain pine beetle, Dendroctonus ponderasae Hopkins, and the pine engraver, Ips pini (Say) (Coleoptera: Scolytidae). Chemoecology, 10: 153-168.
Pureswaran, D.S. and Poland, T.M. 2009. The role of olfactory cues in short-range mate finding by the emerald ash borer, Agrilus planipennis, Fairmaire (Coleoptera: Cerambycidae). Journal of Insect Behavior, 22: 205-216.

Rankin, L.J. and Borden, J.H. 1991. Competitive interactions between the mountain pine beetle and the pine engraver in lodgepole pine. Canadian Journal of Forest Research, 21: 1029-1036.

Reardon, R.C., Leonard, D.S., Mastro, V.C., Leonhardt, B.A., McLane, W., Talley, S., et al. 1998. Using mating disruption to manage gypsy moth: a review. United States Department of Agriculture, Forest Service, Forest Health Technology Enterprise Team, Morgantown, West Virginia, United States of America.

Régnière, J. and Nealis, V. 2002. Modelling seasonality of gypsy moth, Lymantria dispar (Lepidoptera: Lymantriidae), to evaluate probability of its persistence in novel environments. The Canadian Entomologist, 134: 805-824.

Rhainds, M., Kettela, E.G., and Silk, P.J. 2012. Thirtyfive years of pheromone-based mating disruption studies with Choristoneura fumiferana (Clemens) (Lepidoptera: Tortricidae). The Canadian Entomologist, 144: 379-395.

Rhainds, M., Mackinnon, W.E., Porter, K.B., Sweeney, J.D., and Silk, P.J. 2011. Evidence for limited spatial spread in an exotic longhorn beetle, Tetropium fuscum (Coleoptera: Cerambycidae). Journal of Economic Entomology, 104: 1928-1933.

Rocchini, L.A., Bennett, R.G., and Lindgren, B.S. 2003. Douglas-fir pitch moth. Synanthedon novaroensis (Lepidoptera: Sesiidae) in north-central British Columbia: flight period and the effect of trap type and pheromone dosage on trap catches. Environmental Entomology, 32: 208-213.

Rodriguez-Saona, C., Poland, T.M., Miller, J.R., Stelinski, L.L., Grant, G.G., de Groot, P., et al. 2006. Behavioral and electrophysiological responses of the emerald ash borer, Agrilus planipennis, to induced volatiles of Manchurian ash, Fraxinus mandshurica. Chemoecology, 16: 75-86.

Ryall, K.L., Fidgen, J.G., Silk, P.J., and Scarr, T. 2012. Efficacy of (3Z)-lactone and/or (3Z)-hexenol at detecting early infestation of Agrilus planipennis (Col., Buprestidae). Entomologia Expermientalis et Applicata, 147: 126-131.

Ryall, K.L., Lemay, M.A., MaGee, D., Mayo, P., Silk, P. J., and $\mathrm{Wu}$, J. 2010. Sex pheromone chemistry and field trapping studies of the elm spanworm Ennomos subsignaria (Hübner) (Lepidoptera: Geometridae). Naturwissenschaften, 97: 717-724.

Safranyik, L., Shore, T.L., and Linton, D.A. 1996. Ipsdienol and lanierone increase Ips pini Say (Coleoptera: Scolytidae) attack and brood density in lodgepole pines infested by mountain pine beetle. The Canadian Entomologist, 128: 199-207.

Safranyik, L., Shore, T.L., and Linton, D.A. 2004. Measuring trap efficiency for bark beetles (Col., Scolytidae). Journal of Applied Entomology, 128: 337-341. 
Safranyik, L., Shore, T.L., Linton, D.A., and Lindgren, B.S. 1992. The effect of verbenone on dispersal and attack of the mountain pine beetle, Dendroctonus ponderosae Hopk. (Col., Scolytidae) in a lodgepole pine stand. Journal of Applied Entomology, 113: 391-397.

Sama, G. 2002. Atlas of the Cerambycidae of Europe and the Mediteranean Area, Volume 1, Nakladatelstvi Kabourek, Zlín, Czech Republic.

Sanders, C.J. 1981. Spruce budworm: effects of different blends of sex pheromone components on disruption of male attraction. Experientia, 37: 1176-1178.

Sanders, C.J. 1982. Disruption of male spruce budworm orientation to calling females in a wind tunnel by synthetic pheromone. Journal of Chemical Ecology, 8: 493-506.

Sanders, C.J. 1986a. Evaluation of high-capacity, nonsaturating sex pheromone traps for monitoring population densities of spruce budworm (Lepidoptera: Tortricidae). The Canadian Entomologist, 118: 611-619.

Sanders, C.J. 1986b. Accumulated dead insects and killing agents reduce catches of spruce budworm (Lepidoptera: Tortricidae) male moths in sex pheromone traps. Journal of Economic Entomology, 79: $1351-1353$.

Sanders, C.J. 1987. Flight and copulation of female spruce budworm in pheromone-permeated air. Journal of Chemical Ecology, 13: 1749-1758.

Sanders, C.J. 1988. Monitoring spruce budworm population density with sex pheromone traps. The Canadian Entomologist, 120: 175-184.

Sanders, C.J. 1990. Responses of male spruce budworm moths to sex pheromone released from filter paper and rubber septa. The Canadian Entomologist, 122: 263-269.

Sanders, C.J. 1995. Disruption of male spruce budworm orientation to female moths by pheromone and pheromone analogues in a wind tunnel. Physiological Entomology, 20: 71-80.

Sanders, C.J. 1996. Effects of prolonged exposure to different concentrations of synthetic pheromone on mating disruption of spruce budworm moths in a wind tunnel. The Canadian Entomologist, 128: 57-66.

Sanders, C.J., Ennis, T.J., and Daterman, G.E. 1977. Sex pheromone responses of Choristoneura spp. and their hybrids (Lepidoptera: Tortricidae). The Canadian Entomologist, 109: 1203-1220.

Sanders, C.J. and Meighen, E.A. 1987. Controlledrelease sex pheromone lures for monitoring spruce budworm populations. The Canadian Entomologist, 119: 305-313.

Sanders, C.J. and Wilson, G.G. 1990. Flight duration of male spruce budworm (Choristoneura fumiferana [Clem.]) and attractiveness of female spruce budworm are unaffected by microporidian infection or moth size. The Canadian Entomologist, 122: 419-422.

Savoie, A., Gries, R., Gries, G., Borden, J.H., and Pierce, H.D. 1998. Aggregation pheromone of Pityogenes knechteli and semiochemical-based interactions with three other bark beetles. Journal of Chemical Ecology, 24: 321-337.
Sharov, A. and Liebhold, A.M. 1998. Model of slowing the spread of gypsy moth (Lepidoptera: Lymantriidae) with a barrier zone. Ecological Applications, 8: 1170-1179.

Sharov, A., Liebhold, A.M., and Roberts, E.A. 1996. Spread of gypsy moth (Lepidoptera: Lymantriidae) in the central Appalachians: comparison of population boundaries obtained from male moth capture, egg mass counts, and defoliation records. Environmental Entomology, 25: 783-792.

Shepherd, R.F. 1979. Comparison of the daily cycle of adult behavior of five forest Lepidoptera from western Canada and their response to pheromone traps. Mitteilungen der Schweizerischen Entomologischen Gesellschaft, 52: 157-168.

Shepherd, R.F. 1994. Management strategies for forest insect defoliators in British Columbia. Forest Ecology and Management, 68: 303-324.

Shepherd, R.F., Daterman, G.E., Chorney, R.J., and Gray, T.G. 1985. Pest management of Douglas-fir tussock moth, Orgyia pseudotsugata (Lepidoptera: Lymantriidae): monitoring endemic populations with pheromone traps to detect incipient outbreaks. The Canadian Entomologist, 117: 839-848.

Shore, T.L., Hall, P.M., and Maher, T.F. 1990. Grid baiting of spruce stands with frontalin for pre-harvest containment of the spruce beetle Dendroctonus rufipennis Kirby (Coleoptera: Scolytidae). Journal of Applied Entomology, 109: 315-319.

Shore, T.L., Lindgren, B.S., and Safrankyik, L. 1992. The response of mountain pine beetle (Dendroctonus ponderosae) to lodgepole pine trees baited with verbenone and exo-brevicomin. Journal of Chemical Ecology, 18: 533-541.

Shore, T.L. and McLean, J.A. 1983. A further evaluation of interactions between the pheromones and two host kairomones of the ambrosia beetles Trypodendron lineatum and Gnathotrichus sulcatus (Coleoptera: Scolytidae). The Canadian Entomologist, 115: 1-5.

Shore, T.L. and McLean, J.A. 1988. The use of markrecapture to evaluate a pheromone-based mass trapping program for ambrosia beetles in a sawmill. Canadian Journal of Forest Research, 18: 1113-1117.

Silk, P.J., Dunkelblum, E., Kettela, E.G., Northcott, C.J., Butterworth, E.W., and Kuenen, L.P.S. 1989. Identification of sex pheromone component of spruce budmoth Zeiraphera canadensis. Journal of Chemical Ecology, 15: 2435-2444.

Silk, P.J. and Kuenen, L.P.S. 1984. Sex pheromones and their potential as control agents for forest Lepidoptera in eastern Canada. American Chemical Society Symposium Series - American Chemical Society, 238: 35-47.

Silk, P.J. and Kuenen, L.P.S. 1986. Spruce budworm (Choristoneura fumiferana) pheromone chemistry and behavioral responses to pheromone components and analogs. Journal of Chemical Ecology, 12: $367-383$. 
Silk, P.J., Lonergan, G.C., Grant, G.G., Kuenen, L.P.S., and Alford, A.R. 1997. Sex pheromone components of the oak leaf shredder, Croesia semipurpurana (Lepidoptera: Tortricidae). The Canadian Entomologist, 129: 1001-1008.

Silk, P.J., Northcott, C.J., Kettela, E.G., Butterworth, E.W., and Kuenen, L.P.S. 1988. Sex pheromone of purplestriped shootworm, Zeiraphera unfortunana Powell. Journal of Chemical Ecology, 14: 1417-1425.

Silk, P.J., Ross, R.J., Grant, G.G., Wiesner, C.J., and Tan, S.H. 1982. Sex pheromone chemistry of the western spruce budworm Choristoneura occidentalis Free. Journal of Chemical Ecology, 8: 351-362.

Silk, P.J., Ross, R.J., Lonergan, G.C., Tan, S.H., and Wiesner, C.J. 1980. Sex pheromone chemistry of the eastern spruce budworm, Choristoneura fumiferana. Environmental Entomology, 9: 640-644.

Silk, P.J., Ryall, K., Lyons, D.B., Sweeney, J., and Wu, J. 2009. A contact sex pheromone component of the emerald ash borer Agrilus planipennis Fairmaire (Coleoptera: Buprestidae). Naturwissenschaften, 96: 601-608.

Silk, P.J., Ryall, K., Mayo, P., Lemay, M.A., Grant, G.G, Crook, D., et al. 2011a. Evidence for a volatile pheromone in Agrilus planipennis Fairmaire (Coleoptera: Buprestidae) that increases attraction to a host foliar volatile. Environmental Entomology, 40: 904-916.

Silk, P.J., Sanders, C.J., Alford, A.R., Roelofs, W.L., Kuenen, L.P.S., and Tan, S.H. 1985. Identification of sex pheromone components of jack pine budworm, Choristoneura pinus pinus Freeman. Journal of Chemical Ecology, 11: 159-167.

Silk, P.J., Spear-O'Mara, J., Allen, D.C., and Lonergan, G.C. 2000. Potential sex pheromone components of the saddled prominent (Lepidoptera: Notodontidae). The Canadian Entomologist, 132: 681-684.

Silk, P.J., Sweeney, J., Wu, J., Price, J., Gutowski, J.M., and Kettela, E.G. 2007. Evidence for a maleproduced pheromone in Tetropium fuscum (F.) and Tetropium cinnamopterum (Kirby) (Coleoptera: Cerambycidae). Naturwissenschaften, 94: 697-701.

Silk, P.J., Sweeney, J., Wu, J., Sopow, S., Mayo, P.D., and Magee, D. 2011b. Contact sex pheromones identified for two species of longhorned beetles (Coleoptera: Cerambycidae) Tetropium fuscum and $T$. cinnamopterum in the subfamily Spondylidinae. Environmental Entomology, 40: 714-726.

Simpson, R.F. 1976. Bioassay of pine oil components as attractants for Sirex noctilio (Hymenoptera: Siricidae) using electroantennogram techniques. Entomologia Experimentalis et Applicata, 19: 11-18.

Smith, G. and Humble, L.M. 2001. The brown spruce longhorn beetle. Exotic Forest Pest Advisory 5. Catalogue number Fo29-50/5-2000E, Natural Resources Canada, Canadian Forest Service, Victoria, British Columbia, Canada.

Smith, G. and Hurley, J.E. 2000. First North American record of the Palearctic species Tetropium fuscum (Fabricius) (Coleoptera: Cerambycidae). Coleopterists Bulletin, 54: 540.
Smith, M.T., Wu, J., He, W., Xu, X., Gries, G., Gries, R., et al. 2007. Detection and monitoring of the Asian longhroned beetle: update on sentinel tree, attract-and-kill, and artificial lure studies. In Emerald ash borer research and technology development meeting, Cincinnati, Ohio, 29 October-2 November 2006. Edited by V. Mastro, D. Lance, R. Reardon, and G. Parra. United States Forest Service, Forest Health Technology Enterprise Team, Morgantown, West Virginia, United States of America. Pp. 104-105.

Sower, L.L., Daterman, G.E., Funkhouser, W., and Sartwell, C. 1983. Pheromone disruption controls Douglas-fir tussock moth, Orgyia pseudotsugata (Lepidoptera: Lymantriidae) reproduction at high insect densities. The Canadian Entomologist, 115: 965-970.

Sower, L.L., Daterman, G.E., Orchard, R.D., and Sartwell, C. 1979. Reduction of Douglas-fir tussock moth reproduction with synthetic sex pheromone. Journal of Economic Entomology, 72: 739-742.

Stelinski, L.L., Gut, L.J., and Miller, J.R. 2003. Concentration of air-borne pheromone required for long-lasting peripheral adaptation in the obliquebanded leafroller, Choristoneura rosaceana. Physiological Entomology, 28: 97-107.

Stock, A.J., Borden, J.H., Pratt, T.L., Pierce, H.D., and Johnston, B.D. 1990. Endo-brevicomin: an antiaggregation pheromone for the western balsam bark beetle, Dryocoetes confuses Swaine (Coleoptera: Scolytidae). The Canadian Entomologist, 122: 935-940.

Stock, A.J., Pratt, T.L., and Borden, J.H. 1994. Containment and concentration of infestations of the western balsam bark beetle, Dryocoetes confusus (Coleoptera: Scolytidae), using the aggregation pheromone exo-brevicomin. Canadian Journal of Forest Research, 24: 483-492.

Strong, W.B., Millar, J.G., Grant, G.G., Moreira, J.A., Chong, J.M., and Rudolph, C. 2008. Optimization of pheromone lure and trap design for monitoring the fir coneworm, Dioryctria abietivorella. Entomologia Experimentalis et Applicata, 126: 67-77.

Sukovata, L., Kolk, A., and CieSlak, M. 2004. Effect of attract and kill formulations and application rates on trap catches of European pine shoot moth (Lepidoptera: Tortricidae) and shoot damage in Scots pine saplings. Journal of Economic Entomology, 97: 1619-1623.

Sweeney, J.D., de Groot, P., MacDonald, L., Smith, S., Cocquempot, C., Kenis, M., et al. 2004. Host volatile attractants for detection of Tetropium fuscum (F.), Tetropium castaneum (L.), and other longhorned beetles (Coleoptera: Cerambycidae). Environmental Entomology, 33: 844-854.

Sweeney, J.D., de Groot, P., Price, J., and Gutowski, J.M. 2006. Effect of semiochemical release rate, killing agent, and trap design on detection of Tetropium fuscum (F.) and other longhorn beetles (Coleoptera: Cerambycidae). Environmental Entomology, 35: 645-654. 
Sweeney, J.D. and McLean, J.A. 1987. Effect of sublethal infection levels of Nosema sp. on the pheromone-mediated behavior of the western spruce budworm, Choristoneura occidentalis Freeman (Lepidoptera: Tortricidae). The Canadian Entomologist, 119: 587-594.

Sweeney, J.D., McLean, J.A., and Shepherd, R.F. 1990. Factors affecting catch in pheromone traps for monitoring the western spruce budworm Choristoneura occidentalis Freeman. The Canadian Entomologist, 122: 1119-1130.

Sweeney, J.D., Silk, P.J., Gutowski, J.M., Wu, J., Lemay, M.A., Mayo, P.D., et al. 2010. Effect of chirality, release rate, and host volatiles on response of Tetropium fuscum (F.), Tetropium cinnamopterum Kirby, and Tetropium castaneum (L.) to the aggregation pheromone, fuscumol. Journal of Chemical Ecology, 36: 1309-1321.

Thompson, B.M., Grebenok, R.J., Behmer, S.T., and Gruner, D.S. 2013. Microbial symbionts shape the sterol profile of the xylem-feeding woodwasp, Sirex noctilio. Journal of Chemical Ecology, 39: 129-139.

Turlings, T.C.J., Tumlinson, J.H., and Lewis, W.J. 1990. Exploitation of herbivore-induced plant odors by hostseeking parasitic wasps. Science, 250: 1251-1253.

Whittaker, R.H. and Feeny, P.P. 1971. Allelochemics, chemical interactions between species. Science, 171: 757-770.

Wickham, J.D., Xu, Z., and Teale, S.A. 2012. Evidence for a female-produced long range pheromone of Anoplohora glabripennis (Coleoptera: Cerambycidae). Insect Science, 19: 355-371.
Wiesner, C.J., Fullarton, S., Tan, S.H., and Silk, P.J. 1980. Monitoring of atmospheric concentrations of the sex pheromone of the spruce budworm, Choristoneura fumiferana (Lepidoptera: Tortricidae). The Canadian Entomologist, 112: 333-334.

Wiesner, C.J., Palaniswamy, P., Schmidt, J.O., Silk, P.J., and Tan, S.H. 1979. Components of the sex pheromone gland of the eastern spruce budworm, Choristoneura fumiferana (Lepidoptera: Tortricidae). The Canadian Entomologist, 111: 1311.

Wilson, I.M., Gries, G., Gries, R., and Borden, J.H. 1996. Green leaf volatiles as antiaggregants for the mountain pine beetle, Dendroctonus ponderosae Hopkins (Coleoptera: Scolytidae). Journal of Chemical Ecology, 22: 1861-1875.

Witzgall, P., Cork, A., and Kirsch, P. 2010. Sex pheromones and their impact on pest management. Journal of Chemical Ecology, 36: 80-100.

Zhang, A., Oliver, J.E., Aldrich, J.R., Wang, B., and Mastro, V.C. 2002. Stimulatory beetle volatiles for the Asian longhorned beetle, Anoplophora glabripennis (Motschulsky). Zeitschrift Naturforschung a Journal of Biosciences, 57: 553-558.

Zhang, A., Oliver, J.E., Chauhan, K., Zhao, B., Xia, L., and $\mathrm{Xu}, \mathrm{Z} .2003$. Evidence for contact sex recognition pheromone of the Asian longhorned beetle, Anoplophora glabripennis (Coleoptera: Cerambycidae). Naturwissenschaften, 90: 410-413. 